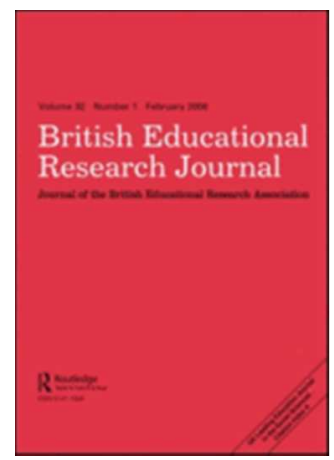

\title{
Developmental Trajectories of Emotional Disengagement from Schoolwork and Their Longitudinal Associations in England
}

\begin{tabular}{|c|l|}
\hline Journal: & British Educational Research Journal \\
\hline Manuscript ID & CBER-2015-0353.R1 \\
\hline Kanuscript Type: & Original Paper \\
\hline Keywords: & $\begin{array}{l}\text { Learner Motivation-Engagement < Learners through the lifecourse, } \\
\text { Longitudinal Study < Research Approaches }\end{array}$ \\
\hline & $\begin{array}{l}\text { This study identified the varied ways in which students' emotional } \\
\text { disengagement and engagement with schoolwork typically developed } \\
\text { between the ages of 14 and 16 years, in the Longitudinal Study of Young } \\
\text { People in England. Using growth mixture modelling we found eight main } \\
\text { trajectories, where students in four trajectories had either increasing or } \\
\text { stable emotional disengagement with schoolwork (41\% of the sample). } \\
\text { Using propensity score matching to create groups balanced on a wide } \\
\text { range of covariates at Wave 1, we compared students who disengaged to } \\
\text { their counterparts without increasing or stable disengagement, to identify } \\
\text { the longitudinal associations between disengaging emotionally from } \\
\text { schoolwork and behavioural engagement, psychological wellbeing, } \\
\text { substance use, career pathways and achievement. Using linear and binary } \\
\text { logistic regressions, we established that students in the disengagement } \\
\text { trajectories developed lower achievement across compulsory secondary } \\
\text { school, had lower levels of educational participation and more participation } \\
\text { in employment at age 17 years. In young adulthood (age 19 - 20 years) } \\
\text { they were less likely to be in university, and more likely to be unemployed. } \\
\text { During secondary schooling, they also engaged more frequently in } \\
\text { substance use, and developed poorer psychological wellbeing which } \\
\text { persisted in the year after compulsory school. However, after compulsory } \\
\text { school the differences in substance use dissipated, and in young adulthood } \\
\text { students in most of the disengagement trajectories has relatively similar } \\
\text { life satisfaction to their counterparts, suggesting that (except perhaps for } \\
\text { the unemployed students) they found a way to develop healthily and } \\
\text { happily after leaving the schoolwork environments they were emotionally } \\
\text { disengaged from. }\end{array}$ \\
\hline
\end{tabular}




1
2
3
4
5
6
7
8
9
10
11
12
13
14
15
16
17
18
19
20
21
22
23
24
25
26
27
28
29
30
31
32
33
34
35
36
37
38
39
40
41
42
43
44
59
45
46
47
48
49
50
51
52
54
56

SCHOLARONE ${ }^{m}$

Manuscripts

10

11

12

13

15

16

17

18

19

20

22

23

25

26

27

29

32

33

34

36

37

40

41

43

44

45

46

47

48

49

50

52

53

56

57

58

60

URL: http://mc.manuscriptcentral.com/cber 


\section{DISENGAGEMENT TRAJECTORES}

Developmental Trajectories of Emotional Disengagement from Schoolwork and Their Longitudinal Associations in England 
DISENGAGEMENT TRAJECTORES

\begin{abstract}
This study identified the varied ways in which students' emotional disengagement and engagement with schoolwork typically developed between the ages of 14 and 16 years, in the Longitudinal Study of Young People in England. Using growth mixture modelling we found eight main trajectories, where students in four trajectories had either increasing or stable emotional disengagement with schoolwork ( $41 \%$ of the sample). Using propensity score matching to create groups balanced on a wide range of covariates at Wave 1, we compared students who disengaged to their counterparts without increasing or stable disengagement, to identify the longitudinal associations between disengaging emotionally from schoolwork and behavioural engagement, psychological wellbeing, substance use, career pathways and achievement. Using linear and binary logistic regressions, we established that students in the disengagement trajectories developed lower achievement across compulsory secondary school, had lower levels of educational participation and more participation in employment at age 17 years. In young adulthood (age $19-20$ years) they were less likely to be in university, and more likely to be unemployed. During secondary schooling, they also engaged more frequently in substance use, and developed poorer psychological wellbeing which persisted in the year after compulsory school. However, after compulsory school the differences in substance use dissipated, and in young adulthood students in most of the disengagement trajectories has relatively similar life satisfaction to their counterparts, suggesting that (except perhaps for the unemployed students) they found a way to develop healthily and happily after leaving the schoolwork environments they were emotionally disengaged from.
\end{abstract}

\title{
Keywords
}

Student engagement, psychological wellbeing, substance use, achievement 


\section{DISENGAGEMENT TRAJECTORES}

\section{Introduction}

In England and internationally, students' feelings about schoolwork have typically become more negative as they moved into, and through secondary schooling (Li \& Lerner, 2011; author \& colleague 2014a; Wang \& Eccles, 2012). Those feelings are captured in students' attitudes, regarding for example how boring, enjoyable, interesting, likable and unlikable schoolwork is (author \& colleague 2014b). Because the attitudes are constructed using emotions as evaluative criteria, they can be conceptualised as emotional attitudes (author \& colleague 2014b). Emotional attitudes can represent the emotions that students experience in class, such as situational boredom and interest (Skinner \& Pitzer, 2012). In this sense they are indicators of engagement experiences, rather than motives in themselves. Accordingly, students' activity emotions and representative emotional attitudes are classified as emotional engagement, which together with cognitive (e.g. attention processes) and behavioural (e.g. daily participation in school activities) engagement makeup the engagement meta-construct (Fredricks, Blumenfeld \& Paris, 2004).

Within emotional engagement, feelings towards schoolwork sit alongside other types of emotional attitudes, such as perceived social support from teachers and peers (RimmKaufman, Baroody, Larsen, Curby \& Abry, 2015), feelings of belonging to school as an institution (Voelkl, 2012), and liking or disliking school as an entity (author and colleague, 2014b). Developing and managing those feelings is a central aspect of students' social and emotional learning (Elias et al., 1997) which more generally associates positively with prosocial behaviour and academic achievement, and negatively with conduct problems and emotional distress (Durlak, Weissberg, Dymnicki, Taylor \& Schellinger, 2011). Although there is growing awareness of the importance of emotional regulation for student wellbeing and achievement, until recently this issue was not incorporated into European educational agendas (Downes, 2011). In the UK, the Social and Emotional Aspects of Learning Programme (SEAL) has units devoted to managing emotions, and has been delivered in 


\section{DISENGAGEMENT TRAJECTORES}

secondary schools since 2007. However in many schools, this programme has not permeated deeper than occasional classroom instruction, leaving its goal of being a whole-school embedded approach unreached (Humphrey, Lendrum \& Wigelsworth, 2010).

A growing number of studies have documented negative associations between these broader aspects of emotional disengagement with schooling and positive youth development. In adolescence, students who are emotionally disengaged with schooling have dropped out of school more often in Finland (Bask \& Salmela-Aro, 2013) and in Canada (Janosz, Archambault, Morizot \& Pagani, 2008), developed lower educational aspirations and achievement in Finland (Tuominen-Soini \& Salmela-Aro, 2014) and in the USA (Wang \& Peck, 2013), and have been marked by poorer mental health (Wang \& Peck, 2013) and reported more delinquent behaviour and drug and alcohol use (Li et al., 2011) in the USA.

Only one of those studies extended to young adulthood, where emotionally disengaged young adults were found to be more likely to attend vocational education and less likely to go to university in Finland (Tuominen-Soini \& Salmela-Aro, 2014). However, this is not necessarily an indicator of negative adaptation, as participation in vocational education after compulsory schooling has associated with improved mental health in England (author and colleagues, in press) raising the question of whether emotional disengagement with schooling can associate with positive outcomes later in the life course. In comparison, several studies have examined the longitudinal associations of emotional engagement with schooling, finding that it consistently predicts greater academic and occupational attainment in young adulthood and adulthood in Australia and England (Abbot-Chapman, Martin, Ollington, Venn, Dwyer \& Gall, 2014; Schoon, 2008; Duckworth \& Schoon, 2012).

As these studies demonstrate, there are different short and longer term associations of emotional disengagement versus emotional engagement with schooling. It is thus important to assess development over time, especially at distinct transition points, such as transitions beyond compulsory schooling. Moreover, it is important to consider groups of students who 


\section{DISENGAGEMENT TRAJECTORES}

disengage and engage separately (e.g. Skinner \& Pitzer, 2013), as other person-oriented research has done (e.g. Li \& Lerner, 2011; Janosz et al., 2008; Ross, 2009; Salmela-Aro \& Upadyaya, 2014a; Wang \& Peck, 2013). By conducting exploratory person-oriented research, it is also possible to ascertain which individual differences underpin different types of emotional disengagement with schooling existing in samples. The use of longitudinal data spanning adolescence and young adulthood can also reveal whether emotional disengagement with schooling has temporary, situational effects, or exerts an influence well past the schooling years, to extend the knowledge base described above. Accordingly, the current study seeks to identify whether there are different trajectories of emotional disengagement with schoolwork in the nationally representative Longitudinal Study of Young People in England (LSYPE), and to ascertain their longitudinal associations with different aspects of development. Furthermore, we situate our outcomes in the developmental periods of early, mid and late adolescence, and young adulthood, which correspond with participants ages at the start of the study period (13/14 years), the end of compulsory secondary schooling $(15 / 16$ years), the transition from compulsory schooling to employment, training, more education or alternative pathways (16/17 years), and the period thereafter until the end of the study period (19-21 years).

\section{Emotional Disengagement from Schoolwork}

This study is concerned with a particular aspect of emotional (dis)engagement: students' emotional experiences of doing schoolwork as represented by their emotional attitudes towards schoolwork. Those emotions are distinct from other types of emotional engagement in school, as we discussed in our introduction. One way to conceptualise schoolwork emotions is to see them as being nested alongside feelings about peers and teachers, within classroom settings. In turn, those classroom oriented feelings are nested alongside feelings regarding other aspects of school experience such as extracurricular activities and student councils, in the larger school context (Skinner \& Pitzer, 2012). 


\section{DISENGAGEMENT TRAJECTORES}

Although we take students' emotional attitudes to represent their lived emotions, it must be made explicit that emotional responses and attitudes are connected by a developmental continuum. Researchers distinguish state emotions, which are in situ emotional responses such as boredom and interest, from trait emotions which are people's tendencies to feel that way (Macklem, 2015). Hidi and Renninger's (2006) Four-Phase Model of Interest Development outlines how these trait and state emotions inform each other developmentally through time. They propose that state emotions are triggered by an activity, then are maintained to some extent throughout it. Over time, individuals develop emerging trait emotions based on their emotional states. Then, those traits become well-established. Over time, trait emotions act as drivers of further state emotions (Linnenbrink-Garcia et al., 2010) which again become internalised within a person's self-schema as trait emotions. Accordingly, it is critical that researcher use carefully worded items in order to capture the subtleties of these different phenomena, as we demonstrate in the following example statements:

1. I had an enjoyable learning experience in my lesson (triggered state emotion)

2. My lesson was enjoyable (maintained state emotion)

3. I tend to enjoy my lessons (emergent emotional trait)

4. Lessons are enjoyable (well-established emotional trait)

However, it is all too easy to blur the distinction between evaluations of the individual and schooling (author, 2014). For as our final example shows, although lessons are the attitudinal object it is actually the individual's tendency that is being expressed.

In this study, we focus on two primary indicators of emotional disengagement from schoolwork: boredom and interest. Although many different emotions can be expressed in attitudes towards schoolwork, including anxiety, frustration, pride, joy, disappointment, connectedness and social isolation (Pekrun \& Linnenbrink-Garcia, 2012), boredom and interest are fundamental to the concept of engagement as deep and sustained involvement in 


\section{DISENGAGEMENT TRAJECTORES}

an activity (Csikszentmihalyi, 1990; Schneider et al., in press). As affective states, boredom and interest mirror each other in many ways; boredom is often accompanied by feelings of emotional pain and displeasure, whereas interest coincides with activity related enjoyment and satisfaction (Pekrun, Goetz \& Titz, 2002). When people experience flow in an activity, they are often unconsciously and intensely interested in what they are doing (Csikszentmihalyi, 1990) which can also be described as cognitive absorption (second author and colleague, 2012). However, the presence of boredom signals emotional disaffection from an activity (Skinner \& Pitzer, 2012).

Boredom and interest together therefore can be perceived as depicting polar opposites of a key emotional engagement continuum. This continuum should have good internal validity, due to boredom and interest being associated with opposite motivational variables (for example lower versus higher activity value) and opposite outcomes (for example lower versus higher mastery motivation), as a range of studies demonstrate (Fulmer \& Tulis, 2013; Linnenbrink-Garcia, Patall \& Messersmith, 2015; O’Keefe \& Linnenbrink-Garcia, 2014; Pekrun, Goetz, Daniels \& Stupnisky, 2010). Likewise, in line with Heckhausen et al.’s (2010) Motivational Theory of Life Span Development, when feelings of boredom and interest act as motives, they do so in opposite manners, with boredom driving people to disengage from an activity, and interest motivating people to engage with it.

\section{Emotional Disengagement, Motivational Theory and Students' Developmental}

\section{Outcomes}

Emotional attitudes and the emotional states they can represent are part of a larger self-system of motivation and engagement (Skinner \& Pitzer, 2012). Within this system, emotional attitudes have mediated the link between motivational resources such as goals and self-concept, and behavioural engagement (Green, Liem, Martin, Colmar, Marsh \& McInerney, 2012). Using Heckhausen, Wrosch and Schulz's (2010) perspective, this mediation can occur as a protective strategy, where people use their attitudes towards an 


\section{DISENGAGEMENT TRAJECTORES}

activity to control the extent to which it influences their motivational resources. For example, students could interpret feelings of academic frustration as an indicator that they are academically less capable. However, if they hold a negative attitude towards learning in lessons, i.e. those lessons are useless and boring, then the negative attribution is given to the activity rather than to their self-concept. Similarly, students may seek to protect their emotional wellbeing from harmful emotions such as boredom, by holding negative attitudes towards schoolwork that justify their lack of cognitive and behavioural engagement. Accordingly, lower emotional engagement has predicted lower effort in learning in Finland (Pietarinen, Soini \& Pyhältö, 2014), and greater off-task behaviour, truancy and absenteeism in the USA (Li \& Lerner, 2013).

In turn, disengaging behaviourally from schoolwork can have feed-forward effects on emotional disengagement (Skinner, Marchand, Furrer \& Kindermann, 2008) as students limit their opportunities to obtain the rewards and environmental supports available to those who succeed academically in lessons. For example a student who puts less effort into their schoolwork may receive more negative feedback from teachers, which leads the student to experience more negative engagement emotions and to develop negative emotional attitudes towards that subject. These types of feedback loops operate to sustain students' emotional disengagement from schoolwork, and can also increase it, when student's negative thoughts and actions, and a lack of environmental support, amplify each other over time (Skinner et al., 2008).

This dynamic system of disengagement from schoolwork and schooling has associated with a range of short and longer term developmental outcomes. For example, when students spent less time at school, they were found to have elevated substance use in the USA which is often a key feature of adolescent peer socialization (Henry, Knight \& Thornberry 2012). Students who were emotionally disengaged have reported lower levels of mental health than their engaged counterparts, and more negative growth in mental health, 


\section{DISENGAGEMENT TRAJECTORES}

across the school years in the USA (Wang \& Peck, 2013), perhaps as they were alienated from important resources for mental health in the school context (Salmela-Aro \& Upadyaya, 2014b) such as positive teacher feedback, support from pro-social peers and extracurricular activities.

Emotional disengagement from schoolwork has also associated with lowered educational aspirations in Finland (Tuominen-Soini \& Salmela-Aro, 2014) perhaps as students who felt little emotional connection to their schoolwork did not wish to spend more time studying after graduation. Regarding achievement, in some US studies there was a clear connection between emotional engagement with schooling and later school achievement (Li \& Lerner, 2011) although in others, this link was not present after accounting for the effects of cognitive and behavioural engagement (Wang \& Eccles, 2012). Accordingly, cognitive and behavioural engagement are found to be effective mediators of the link between emotional engagement and achievement in the self-system model (Green et al., 2012), which in practice could take the form of students distancing themselves emotionally from their schoolwork, subsequently putting less effort into learning, then attaining lower grades.

\section{Disengagement Trajectories and Their Characteristics}

Several person-oriented studies have identified different trajectories of emotional (dis)engagement with schoolwork and schooling, although none have focused solely on emotional attitudes towards schoolwork as we have defined them. Comparisons of profile memberships across two time points have found that students have remained in disengaged profiles but have also moved in and out of them through time (Ross, 2009; Tuominen-Soini \& Salmela-Aro, 2014). Complementary patterns of stable or increasing emotional (dis)engagement are found in studies using growth mixture modelling. Using a measure of caring about school, and being cared for by teachers and classmates, Li and Lerner (2011) found that in a US sample, across Grades 5 (on average at age 11 years) to 8, students either had high engagement with a slight decrease $(6 \%)$, high engagement with a more rapid 


\section{DISENGAGEMENT TRAJECTORES}

decrease $(48 \%)$, moderate engagement with a slight decrease $(41 \%)$ or moderate engagement with a rapid decrease (5\%). Using a compound measure of affective, cognitive and behavioural engagement, Janosz et al. (2008) uncovered seven different trajectories in Canada; wherein $24 \%$ of students had moderate stable disengagement, $3 \%$ disengaged then rebounded, and $2 \%$ disengaged continually. Together, these latent profile and growth mixture studies indicate that there are many subtly different disengagement pathways in secondary schooling.

The disengagement trajectories and profiles reviewed above have been marked by individual differences, although whether these are risk or protective factors has differed depending on the study context. For example regarding ethnicity, in the USA, more African American students were classified into emotional, cognitive and behavioural disengagement from schooling trajectories that began from a lower level of engagement ( $\mathrm{Li}$ and Lerner, 2011), whereas in England, more white students fitted into profiles of emotional disengagement with schooling (Ross, 2009). There, more students of South Asian, Black African and Black Caribbean descent were engaged, in line with the high aspirations for educational attainment transmitted to them by their first generation immigrant parents (Strand, 2007).

The findings for SES in these studies have been reasonably consistent, with lower SES predicting greater and increasing emotional disengagement in the USA (Li \& Lerner, 201) and the UK (Ross, 2009) where around 2.6 million children lived in low-income households during our study period (HM Treasury, 2004). Studies from both countries have documented that growing up in families where parents have lower levels of formal education and fewer economic resources, has negatively associated with the development of young people's achievement and educational aspirations (Ermisch, Jäntti \& Smeeding, 2012; Schoon 2010, 2014), although there is less research on SES and young people's emotional attitudes to schoolwork as we have defined them here. In another study of the LSYPE data, 


\section{DISENGAGEMENT TRAJECTORES}

Chowdry, Crawford and Goodman (2011) found a weak positive association between SES and students' enjoyment and valuing of schooling (2-items) and stronger relationships between SES and students' educational aspirations, however they did not test the associations between SES and students' interest and boredom in lessons.

In the USA and England, being male predicted being more disengaged at the start of secondary schooling and throughout it (Li \& Lerner, 2011; Ross, 2009). Likewise in Finland, more males have fitted into a profile of high cynicism towards school (Tuominen-Soini \& Salmela-Aro, 2014). These gender differences in emotional engagement with schooling in adolescence have been attributed to many factors including male students' desire to obtain popularity through publically dismissing schoolwork and their lack of enjoyment of subjects without a practical component (author and colleagues, 2014 b).

In the Finnish sample, profiles of students who were cynical and burned out were also marked by lower achievement, however there was one profile of engaged-exhausted students who had higher achievement. Similarly, in Canada, both trajectories of engaging and disengaging emotionally, cognitively and behaviourally have been predicted by lower initial achievement (Janosz et al., 2008); demonstrating that having lower achievement does not necessarily lead to disengagement.

\section{The Present Study}

Drawing on the evidence reviewed above, we made the following seven assumptions:

a) There will be multiple trajectories of schoolwork emotional disengagement and engagement within the English sample.

b) The disengagement trajectories will be characterized by lower SES, being white and male, with those individual differences being more prevalent in trajectories of greater disengagement.

c) After accounting for those individual differences, the disengagement trajectories will not associate with prior achievement, as for example, higher achievers can 


\section{DISENGAGEMENT TRAJECTORES}

become burned out and lower achievers can retain emotional engagement with schoolwork.

d) However the disengagement trajectories will associate with lower achievement by the end of school, as students' achievement wanes in response to the broader dynamic system of emotional and behavioural disengagement.

e) The disengagement trajectories will also associate with greater behavioural disengagement, poorer psychological wellbeing and more risk behaviour at school, as school avoidance tactics are played out and environmental supports at school decrease in a continuous feedback loop.

f) After comprehensive secondary school, the disengagement trajectories will associate with reduced participation in upper secondary, further and higher education, and more participation in employment, as students strive to avoid further experiences of activity boredom and disinterest generated in a highly structured educational environment.

g) After school completion, the disengagement trajectories will no longer associate with poorer psychological wellbeing and greater risk behaviour, as students are released from the negative person-environment interactions they experienced at school, and enter a more self-directed and positive phase of development.

To test these assumptions, we used data from the nationally representative Longitudinal Study of Young People in England (LSYPE) to conduct a person-oriented analysis of the development of emotional disengagement from schoolwork. We compared students in the main disengagement trajectories to their counterparts who remained stably engaged or disengaged across compulsory secondary schooling, in order to ascertain whether specific disengagement trajectories associated with gender, ethnicity, and SES; and had the expected relationships with the variables mentioned in our assumptions in four different time periods: (1) in early adolescence at the start of the study, (2) in mid adolescence at the end of 


\section{DISENGAGEMENT TRAJECTORES}

compulsory secondary school, (3) in late adolescence after the transition out of compulsory secondary school, (4) and in young adulthood.

\section{Method}

\section{Participants and Procedures}

Data from Waves 1 to 7 of the nationally representative Longitudinal Study of Young People in England (LSYPE) ${ }^{1}$, were used in the current research. In the LSYPE, participants were surveyed annually from 2004 to 2011 , from age $13 / 14$ to $20 / 21$ years. Schools were used as the primary sampling unit with 646 maintained and 28 independent schools taking part. One design focus was to achieve target numbers of at least 1,000 students in each of five major minority ethnic groups (Indian, Pakistani, Bangladeshi, Black African, Black Caribbean and Mixed) to facilitate research on ethnic minority students, while another was to oversample deprived schools also for analytic purposes. Accordingly, state funded schools were stratified by deprivation status based on the percentage of pupils in that school receiving free school meals. From within each deprivation stratum, schools were selected based on the number of Year 9 ethnic minority students enrolled. Schools in the top quintile of the deprivation distribution were oversampled by $50 \%$. Students attending schools in the maintained sector were sampled using data from the Pupil Level Annual School Census (PLASC), according to their gender, ethnicity and probability of being in a sampled school. In the independent sector, schools and students were sampled based on measures of academic performance and gender.

Study weights used in the study were calculated by the LSYPE administration, who used logistic regression models to calibrate the sample to population totals for ethnicity, gender and region drawn from the National Pupil Database at Wave 1. At each subsequent wave, a non-response weight was calculated using either regression models or cell weighting depending on the available data. The non-response weight was based on the design weight

\footnotetext{
${ }^{1}$ https://www.education.gov.uk/ilsype/workspaces/public/wiki/LSYPE
} 


\section{DISENGAGEMENT TRAJECTORES}

calculated in the previous wave, where applicable, and on a range of data drawn from that wave. In at least the first three waves, the non-response weight combined separate weights calculated for maintained and independent schools, and for students in those schools. More detailed information on weighting can be found in the LSYPE user guide online ${ }^{2}$.

Participants were in compulsory, comprehensive or independent secondary schools between the ages of 14 and 16 years, before transferring to a range of educational, employment or training destinations or becoming not in employment, education or training (NEET) at age 17/18 years. Of the 16,122 participants involved across the seven waves, only those with emotional disengagement data from two or more time points during the three years of compulsory secondary school were included in the study (total $\mathrm{N}=13,734$ ). This selection procedure guaranteed that no cases would be arbitrarily fitted to the disengagement trajectories identified using our analysis technique of Growth Mixture Modelling (GMM). As described in the Analysis and Results section, we used GMM to uncover multiple trajectories of disengagement growth across the three waves of data gathered in secondary schooling. The majority of trajectories varied in their rate of growth, meaning that their level of disengagement changed across time. Therefore, cases needed at least two time points of data in order to identify what their likely pattern of growth was, so that they could be more accurately classified into a specific trajectory.

Compared to those in the analytic sample, participants with missing data were equally balanced in gender, but had slightly lower socioeconomic status $(\mathrm{t}=5.978, \mathrm{df}=2721, p=$ $.000, d=.14)$, childhood achievement $(\mathrm{t}=9.658, \mathrm{df}=2608, p=.000, d=.23)$ and were more likely to be white $(\mathrm{t}=7.043, \mathrm{df}=3262, p=.000, d=.16)$. Calculation of Cohen's d revealed that those effects were negligible or small. The present study used data from Waves 1, 2 and

\footnotetext{
${ }^{2}$ At the time of writing, the LSYPE User Guide is available at https://www.education.gov.uk/ilsype/workspaces/public/wiki/UserGuide
} 


\section{DISENGAGEMENT TRAJECTORES}

3 to represent compulsory secondary school, Wave 4 to represent the school transition period, and Waves 6 and 7 to represent young adulthood.

\section{Measures}

Emotional disengagement from schoolwork. Two items from a 12 item school motivation scale, tapped into emotional attitudes regarding schoolwork and lessons: I am bored in lessons and the work I do in lessons is interesting to me (reversed) at Waves $1(\alpha=$ $.61), 2(\alpha=.61)$, and $3(\alpha=.64)$. The boredom item reflects a state emotion, whereas the interest item referring to 'me' could be interpreted both as a reflection of that person's state interest, and as their trait emotion of being interested in schoolwork. In this study we take both items to represent emotions experienced in school settings. Furthermore, as discussed, trait emotions are often built from repeated emotional experiences, therefore as Steyer and Schmitt (1990) advise, combining attitudes that reflect state and trait emotions will give a richer picture of students' emotions, as neither trait nor state emotions are created in a “situational vacuum" (p. 427).

Effort. This aspect of behavioural disengagement was represented by the item I work as hard as I can in school (reversed) from the school motivation scale.

Truancy. The second aspect of behavioural disengagement was whether the participant played truant in the last 12 months (yes/no) combined with a second item measuring the longest period of truancy in the last 12 months into a 5-item ordinal variable (1 $=$ have not truanted, $5=$ for weeks at a time).

University expectations. At each wave, participants answered how likely it was that they would apply for university on a 4 -point scale of $(1=$ not at all likely, to $4=$ very likely $)$.

Psychological wellbeing. We used two constructs that emerged in prior exploratory factor analysis of general health questionnaire (GHQ) items in the LSYPE (author et al. in press) to indicate how psychologically well participants were. The first tapped into participants' subjective ill-being, through items measuring how much have you been feeling 


\section{DISENGAGEMENT TRAJECTORES}

unhappy and depressed recently, how much have you been feeling reasonably happy recently (reversed), and how much have you been losing confidence in yourself recently. These were rated using a 4 -point scale $(1=$ not at all, to $4=$ much more than usual $)$ at Waves $2(\alpha=.84)$ and $4(\alpha=.82)$. The second measure captured participant's anxiety by asking how much have you feeling constantly under strain recently, whether you have recently lost much sleep over worry, and how much have you recently felt that you couldn't overcome your difficulties (also extracted in author et al., in press). Those items were rated on the same 4-point scale and were measured at Waves $2(\alpha=.76)$ and $4(\alpha=.75)$.

Life Satisfaction. A single item measuring how satisfied participants were with their lives so far $(1=$ very dissatisfied, to $5=$ very satisfied $)$ was administered in Wave 7 .

Peer Victimization. A binary variable of whether the participant had ever been bullied in the past 12 months $(1=$ yes, $0=$ not mentioned $)$ was included in Waves 1-3.

Parental relationship. The average of how well the participant got on with their (step) mother, and (step) father at Waves 1-3 was measured with a 4-point scale $(1=$ very badly, 4 $=$ very well). The small number of participants who reported that they didn't see either of those people ( $1 \%$ of the Wave 1 sample) were coded as missing data.

Drinking alcohol. Two items measuring the prevalence of ever having drunk alcohol and the frequency of drinking alcohol in the past 12 months were combined to form an ordinal, 7-point scale which ranged from never having tried alcohol, to having drunk alcohol most days (Waves 1-3) or almost every day (Waves 6-7). An average measure of drinking in Waves 6 and 7 was used to represent drinking in young adulthood.

Smoking cigarettes. Two items were combined to give an ordinal scale of $1=\mathrm{I}$ have never smoked, to $6=$ I usually smoke more than six cigarettes per week. Smoking was measured at Waves 1-3. 


\section{DISENGAGEMENT TRAJECTORES}

Cannabis use. Whether the participant had every tried Cannabis $(1=$ yes, $0=$ not mentioned) was measured at Waves 1-4 and 6-7. Ever having tried Cannabis at Waves 6 or 7 was taken to represent Cannabis use in young adulthood.

Achievement. Participants' school achievement on standardized national tests at ages 11, 14 and 16 years was linked to the LSYPE from National Pupil Data (NPD).

Gender. Participants reported whether they were female (1) or male (0). The average gender across waves was taken to represent participants' gender.

Socioeconomic Status (SES). The LSYPE administration used the National Statistics Socioeconomic Status Classification method to code parents' open ended reports of occupation, supervisory status and number of employees into eight ordinal categories ranging from professional occupations (8) to long term unemployed (1). In this study, we recoded SES into three dummy variables to reflect three distinct occupational states: professional occupations, routine occupations, and unemployment $(1=$ within category, $0=$ not in category).

Ethnicity. Participants reported whether they were white, mixed, Indian, Pakistani, Bangladeshi, Black Caribbean, Black African or other ethnicity. These responses were dichotomized into white (1) versus ethnic minority (0) in order to preserve larger group sizes for analysis.

Late Adolescent Career Pathways. One year after compulsory secondary school (Wave 5), participants reported whether they were in full time education, in full time work, were on an apprenticeship training scheme or were not in education, work or employment (NEET). Each pathways was coded into binary data $(1=$ on that pathway, $0=$ not on that pathway).

Young Adult Career Pathways. In Waves 6 and 7, participants reported whether they were doing a course at university, in education, in paid work, on a training course or scheme, doing an apprenticeship, engaged in another type of activity or were not in education, 


\section{DISENGAGEMENT TRAJECTORES}

employment or training (NEET). Participants were given a positive score (1, versus 0$)$ if they mentioned that pathway in either Wave 6 or 7.

\section{Analysis and Results}

\section{Disengagement Trajectories in Compulsory Secondary School}

Growth mixture modelling (GMM) in Mplus version $7.3^{3}$ was used to determine the most common (dis)engagement trajectories in secondary school. GMM assumes that distinct trajectories exist within a dataset, and seeks to classify participants into trajectories that have good internal homogeneity, for the number of trajectories that the researcher specifies (Muthén \& Muthén, 2000). The models were unconditional, and were run using fullinformation maximum likelihood estimation which uses all available data (Little \& Rubin, 2014), and assumes that data are missing at random or completely at random (Schafer \& Graham, 2002). Multiple starting values were used to avoid the occurrence of local solutions. Different models, containing an increasing number of trajectories, were evaluated for their best fit to the data, and compared to each other. Well fitted models were identified as those with good classification accuracy, overall (entropy of .7 or above) and for each class (average posterior probabilities of group membership at .7 or above). Successive solutions were deemed to fit better than the former when they returned a lower statistic for the Akaike information criterion (AIC), Bayesian information criterion (BIC) and sample size adjusted BIC; and significant values for the Vuong-Lo-Mendell-Rubin (VLMR) and Lo-MendellRubin (LMR) likelihood ratio tests (Nagin \& Odgers, 2010).

\section{Table 1 around here}

Of the 10 models evaluated, the model containing 8 trajectories emerged as the best fit (Table 1), with the highest entropy (0.89), a notably lowered BIC (44164) and significant VLMR and LMR $p$ values (both at 0.000 ). We named each trajectory according to the

\footnotetext{
${ }^{3} \mathrm{https}: / /$ www.statmodel.com/
} 


\section{DISENGAGEMENT TRAJECTORES}

steepness of its slope (stable, mild, rapid), and as to whether its intercept was above or below the middle score in the disengagement scale (disengaged versus engaged). The largest trajectory had relatively stable, moderate levels of engagement (stable engaged, $\mathrm{N}=5840$, 42.5\%) where the slope reached significance probably only because of the large number of participants. The next three largest trajectories had similar, moderate levels of engagement at baseline but then two disengaged either gradually (disengaging mildly, $\mathrm{N}=2558,18.6 \%$ ) or steeply (disengaging rapidly, $\mathrm{N}=1306,9.5 \%$ ) over time. The third had a rapid increase in engagement (engaging rapidly 1, $\mathrm{N}=1492,10.9 \%$ ). The two next largest trajectories were disengaged at baseline, and either remained stable in their disengagement (stable disengaged, $\mathrm{N}=868,6.3 \%$ ) or disengaged more through time (disengaging disengaged, $\mathrm{N}=898,6.5 \%$ ). Finally, two smaller trajectories had increasing engagement from an engaged baseline (engaging rapidly $2, \mathrm{~N}=485,3.3 \%$ ) or a disengaged baseline (engaging rapidly $3, \mathrm{~N}=287$, $2.1 \%$ ). Across trajectories, the broader pattern was that students were either stable engaged or engaging (59\%); stable disengaged or disengaging (41\%). This analysis fitted our first assumption, that there would be different trajectories of (dis)engagement.

\section{Table 2 and Figure 1 around here}

\section{Disengaging/Disengaged Students in Early Adolescence}

In order to identify the characteristics and correlates of the four disengagement trajectories, we allocated a comparison trajectory to each (Table 7). To isolate the effects of increasing disengagement, we compared the disengaging mildly, disengaging rapidly and disengaging disengaged trajectories to their stable counterparts with the closest disengagement intercept. There, we paired the disengaging mildly and disengaging rapidly trajectories with the stable engaged trajectory, and the disengaging disengaged trajectory with the stable disengaged trajectory. Then, we paired the stable disengaged trajectory with the stable engaged trajectory to examine the differences between stable disengagement versus engagement, through time. 


\section{DISENGAGEMENT TRAJECTORES}

Using stepwise multiple linear regression, we tested for the effects of individual differences and age 11 achievement on trajectory membership. In the tests of increasing disengagement, we controlled for Wave 1 disengagement in the first step, to isolate the effects of slope, then entered the individual differences and achievement in the second step. We removed this first step when comparing the two stable groups, in order to focus on level of disengagement. The regressions tested assumption $b$ that the trajectories would be predicted by being male, having lower SES and being white, and assumption c that there would be no difference in age 11 achievement once controlling for individual differences. Hereon we use Cohen's (1992) terminology for reporting the effect sizes of mean differences $($ small $=.20$, medium $=.50$, large $=.80)$, which are indicated by the Beta weights in the multiple regression models.

Disengaging mildly and rapidly. After controlling for Wave 1 disengagement, there were small and moderate effects of being white (disengaging mildly: $\mathrm{d}=.41$, disengaging rapidly: $\mathrm{d}=.58)$ and a moderate effect of having fewer unemployed parents $(\mathrm{d}=.50)$ in the disengaging rapidly trajectory. Both models were significant but accounted for a minimal percentage of the variance (disengaging mildly: $F(7,7840)=22.768, p<.000, \mathrm{R} 2=.02$; disengaging rapidly: $F(7,6406)=11.482, p<.000, \mathrm{R} 2=.01)$. Together, the individual differences and achievement in the second step added less than .01\% to the variance explained.

\section{Tables 3 and 4 around here}

Stable disengaged. Here, without controlling for Wave 1 disengagement, the only notable predictor was being white $(\mathrm{d}=.35)$. Interestingly, the different SES statuses made no difference to whether students were stable engaged or stable disengaged. This model $(F(6,6120)=14.058, p<.000)$ accounted for under $1 \%$ of the variance in trajectory membership.

\section{Table 5 around here}




\section{DISENGAGEMENT TRAJECTORES}

Disengaging disengaged. After controlling for Wave 1 disengagement, the only significant predictor of trajectory membership was having lower achievement, although this effect was minimal $(\mathrm{d}=.01)$. There were however a raft of small to large insignificant effects: of being white $(\mathrm{d}=.26)$, having more parents in professional occupations $(\mathrm{d}=.16)$, fewer parents in routine occupations $(d=.31)$ and fewer parents in unemployment $(d=1.10)$. The model was significant $F(7,1560)=26.454, p<.000, \mathrm{R} 2=.10)$ and explained more variance than the other models, but again, the second step accounted for . $01 \%$ of the variance explained.

\section{Tables 6 around here}

\section{Disengaging/Disengaged Students in Mid Adolescence}

As observed in the regressions, the continually disengaging trajectories differed from their stable comparisons on Wave 1 disengagement. This raised the possibility that any developmental differences observed might be accountable to both this different level of initial disengagement, and to the subsequent disengagement process. Accordingly, we removed this confounding effect by using propensity score matching (PSM) to balance each pair of trajectories on Wave 1 disengagement. We also balanced the pairs on the full range of longitudinal variables that had Wave 1 data, so that theoretically we were comparing very similar groups of students, who then followed different developmental pathways. These variables were gender, SES, white ethnicity, age 11 achievement, effort, truancy, university aspirations, parental relationship, bullying, smoking, drinking and drug use. Only the stable disengaged versus stable engaged trajectories were not balanced on Wave 1 disengagement, as there we sought to identify the longitudinal associations of level of disengagement, rather than slope.

The PSM R plugin for SPSS developed by Thoemmes (2012) was used for the matching. First, we replaced the Wave 1 missing values with average scores computed from five multiple imputed datasets created in SPSS version 23.0. Then, we created new data files 


\section{DISENGAGEMENT TRAJECTORES}

for each pair of trajectories. Within those files, the trajectories were entered as binary data (1 $=$ disengagement, $0=$ comparison). Then, the Wave 1 variables were regressed on the trajectory variable to create propensity scores that indicated which comparison case was closest to each disengagement case (nearest neighbour matching). Strict protocols were employed to produce a precise match (one to one matching strategy, calliper of 0.2 , and discarding cases outside of the common area of support). The final sub-samples for each pair of trajectories are displayed in Table 7.

\section{Tables 7 around here}

The success of the PSM was evaluated as follows. The relative multivariate imbalance statistic for each trajectory pair was smaller after matching which indicated a reduction in between-trajectory variance. Next, the matched trajectory variables were imported into the main dataset and were tested for balance with the original, non-imputed Wave 1 data.

Levene's tests and independent samples t-tests confirmed that the matched trajectories were equal in their Wave 1 variable distribution and mean values, with the following exceptions: cannabis use was higher for the disengaging rapidly trajectory $(\mathrm{M}=.11, \mathrm{SD}=.31)$ versus the stable engaged trajectory $(\mathrm{M}=.07, \mathrm{SD}=.25 ; \mathrm{B}=.507, \mathrm{SE}=.142$, Wald $=12.65, \mathrm{df}=1, p=$ $.000, \mathrm{~d}=.82)$, and smoking was negligibly higher for the disengaging mildly trajectory $(\mathrm{M}=$ $1.29, \mathrm{SD}=1.03)$ versus the stable engaged trajectory $(\mathrm{M}=1.23, \mathrm{SD}=.94 ; \mathrm{B}=.061, \mathrm{SD}=$ $.029, \mathrm{t}=4.258, p=.039, \mathrm{~d}=.06)$.

Using linear and logistic regressions, we then examined the trajectory pairs for differences in the Wave 3 variables, in order to test assumption d, that disengaging students would have lower later achievement to other trajectories, and assumption e, that they would develop greater behavioural disengagement, poorer psychological wellbeing and more risk behaviours at the end of compulsory secondary school.

Disengaging mildly and rapidly. At Wave 3, disengaging either mildly or rapidly, predicted greater emotional disengagement, lower effort, more truancy, lower university 


\section{DISENGAGEMENT TRAJECTORES}

aspirations and GCSE achievement; poorer quality parental relationships; more frequent victimization; more smoking, drinking and cannabis use; and higher anxiety and subjective ill-being, than being stably engaged (Tables 8 and 9). The effect size average (not including the effect for emotional disengagement) was greater for the disengaging rapidly trajectory ( $\mathrm{d}$ $=0.28)$, compared to the disengaging mildly trajectory $(d=0.16)$, indicating that the steeper the disengagement was, the more negative the outcomes were at the end of compulsory secondary schooling.

\section{Tables 8 and 9 around here}

Stable disengaged. Although they were matched to the stable engaged trajectory at Wave 1, the stable disengaged group developed more negative scores on all variables by Wave 3 . The mean effect size was 0.26 , indicating on average a small effect of being stably disengaged on development.

\section{Table 10 around here}

Disengaging disengaged. By Wave 3, the students who were disengaged at Wave 1 but then continued to disengage, had more negative scores on emotional disengagement, effort, truancy and GCSE scores, and were more likely to be bullied, drink alcohol, take drugs, and feel depressed. However, both the disengaging and stable disengaged trajectories developed more negative relationships with parents (disengaging $\mathrm{M} \Delta=-.08 ; \mathrm{t}=-2.689, \mathrm{df}=$ $500, p=.007 ;$ stable $\mathrm{M} \Delta=-.08 ; \mathrm{t}=-2.689, \mathrm{df}=527, p=.005)$, decreased university aspirations (disengaging $\mathrm{M} \Delta=-.28 ; \mathrm{t}=-5.768, \mathrm{df}=479, p=.000 ;$ stable $\mathrm{M} \Delta=-.28 ; \mathrm{t}=-$ 5.763, $\mathrm{df}=527, p=.000$ ), increased levels of smoking (disengaging $\mathrm{M} \Delta=.91 ; \mathrm{t}=10.028$, $\mathrm{df}=457, p=.000 ;$ stable $\mathrm{M} \Delta=1.09 ; \mathrm{t}=11.772, \mathrm{df}=479, p=.000)$ and had stable anxiety. The effect size average was 0.15 , similar to the disengaging mildly trajectory.

Table 11 around here

\section{Disengaging/Disengaged Students in Late Adolescence}




\section{DISENGAGEMENT TRAJECTORES}

We next used linear and logistic regressions to test assumption $\mathrm{f}$, that disengaging students would have lower participation in upper secondary and further education and more participation in employment, and assumption g, that they would have similar psychological wellbeing and risk behaviours to their counterparts, after finishing compulsory secondary school (Wave 4).

Disengaging mildly and rapidly. As assumed, in Wave 4, both disengaging trajectories were less likely to be in full time education (disengaging mildly by $5 \%, \mathrm{~d}=.66$; disengaging rapidly by $13 \%, \mathrm{~d}=2.30$ ) and more were working (disengaging mildly by $25 \%$, $\mathrm{d}=1.32$; disengaging rapidly by $75 \%, \mathrm{~d}=5.71$ ) than their stable engaged counterparts. However, the disengaging rapidly students were also $40 \%$ more likely to be unemployed $(\mathrm{d}=$ 3.44) and both groups had higher anxiety and subjective ill-being. The effect sizes were larger in all cases for the disengaging rapidly versus disengaging mildly students.

Stable disengaged. In Wave 4, 12.4\% fewer stable disengaged students attended full time education $(d=.94)$, and $66 \%$ more were employed $(d=4.38)$. They also had greater anxiety, but similar subjective ill-being and unemployment to their stable engaged counterparts.

Disengaging disengaged. Compared to the stable disengaged students, in Wave 4, fewer disengaging disengaged entered full time education (by $33 \%, \mathrm{~d}=.87$ ) and more were in full time work (by $38 \%, \mathrm{~d}=1.23$ ), but they also had poorer psychological wellbeing.

\section{Disengaging/Disengaged Students in Young Adulthood}

Our final set of regressions tested the same assumptions as for late adolescence ( $\mathrm{f}$ and g). However, anxiety and subjective ill-being were not measured in Waves 6 and 7, therefore we included life-satisfaction instead, as a complementary measurement of psychological wellbeing.

Disengaging mildly and rapidly. In young adulthood, 15\% fewer rapidly disengaging students attended university $(\mathrm{d}=.65)$ as assumed, but both disengaging trajectories also had a 


\section{DISENGAGEMENT TRAJECTORES}

greater percentage of unemployment (disengaging mildly $=20 \%, \mathrm{~d}=.78$; disengaging rapidly $=50 \%, \mathrm{~d}=1.83)$. Disengaging rapidly students also had lower life-satisfaction $(\mathrm{d}=$ .25) although this was a small effect. Otherwise, in this time period, the disengaging trajectories looked similar to their stable engaged counterparts in attending university and further education, employment, annual salary and substance use.

Stable disengaged. As for the disengaging trajectories, the notable effects of being stably disengaged in adolescence dissipated in young adulthood. There, only reduced university participation (by $19 \%, d=.79$ ) and a negligible negative effect on life satisfaction $(d=.15)$ emerged.

Disengaging disengaged. Compared to the stable disengaged students, 29\% fewer disengaging students attended further education $(d=1.12)$ and $46 \%$ more were unemployed $(\mathrm{d}=1.48)$. However, as for the other trajectory pairs, this pair had very similar career activity, salary, substance use and life-satisfaction in young adulthood.

\section{Discussion}

This study aimed to explore the most common trajectories of emotional disengagement from schoolwork in compulsory secondary school in England and establish their longitudinal associations with individual characteristics, achievement, psychological wellbeing, risk behaviours and career pathways. It tested six assumptions about those associations, based on evidence from prior studies of schoolwork and schooling emotional disengagement and engagement; across three time periods (early adolescence, late adolescence and young adulthood) using longitudinal data from the LSYPE.

\section{Multiple Disengagement Trajectories}

First, we identified eight varied disengagement and engagement trajectories using growth mixture modelling, confirming our assumption that there would be multiple trajectories of engagement and disengagement within the sample (assumption a). Our 


\section{DISENGAGEMENT TRAJECTORES}

approach extended the latent transition analysis of the LSYPE by Ross (2009), by demonstrating slopes of disengagement in compulsory secondary school.

The first two disengagement trajectories were emotionally engaged with schoolwork at age 14/15 years in Wave 1 but then disengaged at different rates. This experience of being initially engaged, but then losing interest in schoolwork, is widespread in the literature on school transition. Immediately following transfer to secondary school, students often report a 'honeymoon' period (Hargreaves, 1984) where they view their experiences in lessons through rose tinted glasses. However, this initial excitement can quickly wear off, as students realise that not all aspects of school environment are a good fit with their personal and developmental needs, as outlined by stage-environment fit theory (Eccles, Wigfield, Midgley, Reuman, Mac Iver \& Feldlaufer 1993; author \& colleague, 2014a).

Second, we identified a group of students who remained at a stable level of disengagement through time. As the first wave of data was collected at age 14 years, rather than at 12 years in the first year after transfer to secondary school, it is impossible to tell whether this group had been engaged beforehand. However, they had the most consistent disengagement which called our attention to exploring which mechanisms might have kept them at that stable level, by comparing them to the disengaging disengaged trajectory.

A final group of students were also disengaged early on in secondary school, however their disengagement increased through time, to extremely high levels. This indicates that whatever personal and social mechanisms were acting to influence their emotional disengagement from schoolwork became stronger, possibly by continually reinforcing and heightening each other (Skinner et al. 2008). Interestingly, this trajectory of disengaging from a disengaged baseline has not been observed in other large scale studies (Li \& Lerner, 2011; Janosz et al., 2008), therefore is not necessarily related to the greater heterogeneity of larger samples in other countries.

\section{Individual Characteristics of Disengagement}




\section{DISENGAGEMENT TRAJECTORES}

Our next assumption (b) was that the trajectories would be marked by known risk factors for disengagement from schooling and schoolwork, including being male, having greater social disadvantage and being white. However, in contrast to samples from the US (Li \& Lerner, 2011) and Canada (Janosz et al., 2008), and to Ross' (2009) study of the same LSYPE data, after controlling for the initial level of disengagement in comparisons of trajectories with different slopes, no notable gender differences were observed and three of the four disengagement trajectories had no SES differences. Further investigation using SES as an ordinal variable revealed that SES did not correlate with our measure of emotional disengagement at any wave. Also, the full range of SES categories fell into a relatively normal distribution for each trajectory, as the computation of histograms further demonstrated. Therefore, the lack of SES differences in our study was not accountable to our multiple regression method where gender and ethnicity were entered before SES in the models.

Our finding of a lack of relationship between individual background factors and emotional attitudes towards school is comparable to Gorard and Huat See's (2010) study of around 3,000 students in 45 secondary schools across England. There, background factors including gender, SES and eligibility for free school meals accounted for only $4 \%$ of the variation in student perceptions of how interesting their lessons were, and $10 \%$ of the variation in how much they enjoyed school. As these authors commented, this finding is in stark contrast to the positive associations generally found between SES and other aspects of engagement such as educational aspirations (Chowdry et al., 2010) and the amount of time not being in education, employment or training (NEET) (Schoon, 2014).

So why do our findings contrast with prior studies that considered emotional engagement in their analyses? This may be explained by measurement differences. Ross combined items on students' attitudes towards school, school work and lessons (a 10-item scale) with a measurement of their truancy and plans for what they would do after finishing 


\section{DISENGAGEMENT TRAJECTORES}

compulsory schooling. In England, students' expectations for attending higher education are associated with their social class (Chowdry et al., 2011; Parker, Jerrim, Schoon \& Marsh, 2016) therefore possibly explaining why SES differences were observed in Ross' (2009) study and not in ours, as we did not include aspirations in our emotional engagement measure. Similarly, Janosz et al. (2008) used a combined measure of emotional, cognitive and behavioural engagement, and Li and Lerner (2011) measured emotional engagement as students' emotional attitudes towards teachers and peers, not schoolwork. In all of these studies, social factors such as SES and gender may have influenced specific items or sets of items, outside of the domains of boredom and interest.

In our study, being white was the only consistent predictor of trajectory membership with effect sizes that ranged from small to medium across the four disengagement trajectories. This could represent the protective process of being an ethnic minority student in England, as they are often second generation immigrants, whose attitudes towards schooling are positively influenced by their parents' high expectations for achievement, even if they struggle to achieve at similar levels as their white peers (Strand, 2007).

\section{Disengagement and Achievement: A Dynamic Developmental System}

Third we predicted that the disengagement trajectories would have similar achievement to their comparison trajectories at baseline (assumption c) but that their achievement would wane across the school years (assumption d). Accordingly, in the LSYPE, students developed a variety of disengagement trajectories, regardless of their childhood achievement. However, by the end of compulsory school, students in all disengaging trajectories had worse achievement on average than their counterparts. Our suggestion is that this decline in achievement was part of a broader dynamic system of emotional and behavioural disengagement, for in line with assumption e, as our findings also demonstrated, by Wave 3, disengaged students also tried less hard at school and attended less often, and had lower aspirations for academic success, which presumably would have 


\section{DISENGAGEMENT TRAJECTORES}

negatively impacted their achievement. This might also explain why emotional engagement did not predict achievement in Wang \& Eccles (2012), after they added behavioural engagement to their model, as behavioural engagement may have fully mediated the connection between emotional attitudes and achievement.

\section{Longitudinal Associations with Education and Employment}

Next we assumed (f) that becoming or being emotionally disengaged from schoolwork in compulsory secondary school would associate with lower levels of participation in full time education and greater uptake of employment, after compulsory school had ended. At age 17/18 years, our assumption was met for all disengagement trajectories. This might be directly related to the lower end of school achievement observed for the disengagement trajectories, as students in England need to get reasonably high grades in order to continue to A Level courses. However, the trend might also have been part of an avoidance strategy (Heckhausen et al., 2010), where students sought to protect themselves against having more setbacks and negative emotional experiences either at the same school, or in sixth form and further education colleges that have some similarities to schools such as timetables, and examinations which can act as acute stressors in late adolescence (McCoy, Smyth, Watson \& Darmody, 2014). Then, the lower rates of participation in full time education at age 17/18 might have carried over to the lower rates of participation in university and further education, observed in young adulthood for several of the disengagement trajectories. In this manner, emotional disengagement from schoolwork at compulsory school appeared to have a specific longer term effect on students' outcomes, by affecting their progress in school and career pathways afterwards. Likewise in Finland, having a cynical attitude towards school has predicted dropping out of education (Bask \& Salmela-Aro, 2013).

Disengaged students were also more likely to enter employment in late adolescence as expected, but not in young adulthood; perhaps as more comparison students finished their 


\section{DISENGAGEMENT TRAJECTORES}

educational courses and entered the workforce. Another interesting result surfaced in young adulthood, where the disengaging mildly, disengaging rapidly and disengaging disengaged students were all more likely to be unemployed than their comparison groups. Possibly their lowered educational aspirations and achievement may have been a risk factor for becoming unemployed, as has been found already in the LSYPE and in other British cohorts (Duckworth \& Schoon, 2012; Schoon 2014).

\section{Longitudinal Associations with Psychological Wellbeing}

Finally, we assumed (g) that disengaged students would have similar levels of psychological wellbeing and risk behaviours to their counterparts in young adulthood, despite having poorer wellbeing at the end of compulsory school, indicating some type of psychological recovery as they engaged in new activities that were presumably less boring and more interesting to them. However, in the year after compulsory school, students in all the disengagement trajectories had higher anxiety and subjective ill-being than their counterparts. Possibly these were recent, temporary spill over effects from their negative emotional experiences of doing schoolwork (Salmela-Aro \& Upadyaya, 2014b) which is a major task in adolescence, for two years later in young adulthood, only the disengaging rapidly students were notably less satisfied with their lives than their comparison students. What is perhaps most significant, is that the stable disengaged students had very similar life satisfaction to those who were stable engaged, indicating that despite their higher levels of anxiety and subjective ill-being in late adolescence and different career pathways, they evaluated their lives as being just as good in young adulthood. This may also relate to their greater uptake of vocational pathways, which has associated with improved mental health for LSYPE students (author et al., in press) and for similar aged adolescents entering the vocational schooling system in Finland (Salmela-Aro \& Tynkkynen, 2012).

A similar pattern appeared for substance use, where the higher levels of smoking, drinking and drug use observed at the end of compulsory schooling were not present in young 


\section{DISENGAGEMENT TRAJECTORES}

adulthood. Our suggestion is that those enhanced levels at compulsory school were part of the broader dynamic disengagement system described earlier, where students avoided school and spent more time engaged in risk behaviours outside of school (Henry et al., 2012). However, after leaving school, these students might have resumed a more normative level of substance use. Their engaged counterparts who were more likely to attend university might also have overtaken them in substance use, for in the USA, young adults attending university have reported higher levels of substance use than their non-university peers (Carter, Brandon \& Goldman, 2010). Regardless, the findings present a picture of improved health behaviours after leaving school for emotionally disengaged students.

\section{Limitations}

The findings presented above should be interpreted in light of several limitations. First, it is possible that by choosing a greater number of trajectories, we might have generated further, substantive findings about how different types of trajectories related to psychosocial functioning, despite the larger solutions being less well fitted statistically. Second, the main findings were generated using propensity score matched sub-samples. This reduced the representativeness of our findings to the larger sample and its underlying population (Thoemmes \& Kim, 2011), however our main findings were consistent across the comparison groups indicating that our analysis was reasonably robust to those slight changes in sample membership. Third, our attrition analysis indicated that students missing in subsequent waves were more disadvantaged socially and academically, therefore our findings are conservative estimates of the risks associated with disengaging emotionally from schoolwork. Fourth, there may have been other mediating variables not measured in this study that influenced the changes in disengagement and observed group differences in associations with measured outcomes, such as between group differences in alternative education, the quality of services to support students' social, emotional and behavioural development, and fluctuations in the levels of child poverty throughout the period of study. Fifth, there are 


\section{DISENGAGEMENT TRAJECTORES}

many other types of emotions that underpin the formation of emotional attitudes towards schoolwork, including for example anxiety, frustration, pride and joy (Pekrun \& LinnenbrinkGarcia, 2012). As discussed we took boredom and interest to be general indicators of emotional (dis)engagement with schoolwork, in line with the available data. However, it may be of interest to other researchers to repeat this type of study using more nuanced and multidimensional measures of schoolwork emotional disengagement.

\section{Conclusions}

In this analysis of the LSYPE, we found several distinct trajectories of emotional engagement with and disengagement from schoolwork during compulsory secondary schooling. However, unlike prior studies in the US (Li \& Lerner, 2011), Canada (Janosz et al. 2008) and the UK (Ross, 2009), we found very few individual differences to mark those trajectories. In our discussion we posited that measurement differences might explain this lack of comparison, because unlike in those studies, we focused exclusively on students' interest and boredom. Also as discussed, in a more comparable study using another large English sample, Gorard and Huat See (2010) found that gender and SES made very little difference to students' interest in lessons. But we still need to offer an explanation as for why boredom and interest might have little connection to background factors when they are studied by themselves.

Possibly, situational interest and boredom are closely connected to students' basic psychological reactions to curricula and pedagogy, such as whether or not they inspire adequate motivation, cognitive challenge (Shernoff et al., 2016) and internal regulation while learning (Westling, Pyhältö, Pietarinen \& Soini, 2013). These basic reactions and the emotions that they help generate may occur independently of students' aspirations and career identities (e.g. Parker et al., 2016; Schoon \& Eccles, 2014) that commonly relate to their SES and gender. The finding that these emotional attitudes do not vary by background characteristics in England, therefore could simply indicate that there is no systematic bias in 


\section{DISENGAGEMENT TRAJECTORES}

the way that students of different genders and social classes are taught or how they perceived their teaching (Gorard \& Huat See, 2010).

The existence of varied (dis)engagement trajectories unaligned with background factors in this study could therefore indicate that particular person-environment misalignments were occurring during the process of doing schoolwork, that were unrelated to cultural mechanisms such as gender and SES. Possibly, students in the disengagement trajectories experienced misfits between their desired for and experienced emotional support from teachers and peers, or between their need for cognitive stimulation and the manner in which schoolwork was delivered in their classrooms (Eccles et al., 1993). It could also indicate a difference in students' personal resources that can be used to sustain educational resilience, such having as a self-regulated learning orientation (Skinner \& Pitzer, 2012).

These suggestions may have relevance for school based interventions to improve students' emotional experiences of doing schoolwork. For example, creating a more personalised learning environment so that every adolescent student can utilise their personal motivational styles and learning preferences while doing schoolwork; improving the quality of teacher-student relationships across the board by helping teachers become more familiar and empathetic with their students through continued professional development modules; and developing schoolwork units designed to facilitate positive emotions such as enjoyment, curiosity, interest and pride. The continuation of our observed disengagement trajectories through secondary school, and their associations with negative outcomes around the end of schooling period suggest that it is important to start these interventions early on in secondary school to protect against disengagement trajectories from forming and self-accentuating.

During school, any type of emotional disengagement from schoolwork was positively associated with students' anxiety and subjective ill-being, and negatively associated with their achievement, especially for students with the most increased disengagement. Here, we presumed that a broader dynamic system of disengagement was being played out. This may 


\section{DISENGAGEMENT TRAJECTORES}

have begun by students continually experiencing negative state emotions while doing schoolwork, such as boredom, or lacking positive state emotions such as interest. Over time, those state emotions became absorbed into students' negative emotional attitudes towards schoolwork. In order to avoid experiencing negative emotions, students might have disengaged cognitively from schoolwork, putting in less effort and attention thus reducing their opportunities to make good academic progress. Regarding their temporary loss of wellbeing, disengaging from schoolwork may have reduced students' opportunities to capitalise on social and emotional resources such as support from teachers and proschoolwork classmates, and the chance to boost their self-esteem through academic progress.

However, in young adulthood, those negative effects on wellbeing dissipated, suggesting that even though these students had followed less academic pathways, they were just as satisfied with their lives, and lived just as healthily (or unhealthily) as those who had remained engaged with their schoolwork in compulsory school. As suggested in the discussion, this might relate to their greater uptake of vocational pathways and lower continuation in academic education, which has associated with improved mental health in the LSYPE (author and colleagues, in press). After leaving comprehensive school, the disengaged students might have selected their main activities to optimise their chances of avoiding negative emotions related to schoolwork and similar types of study. These eventual pathways might have originated earlier in their school experiences through the development of lower educational aspirations and a lack of expectations to continue with academic education. As proposed by Heckhausen, et al., (2010) their disengagement at secondary school might have been an avoidance tactic, protecting their self-identity. The findings of this study suggest that this avoidance tactic can be extended well past the critical period that fuelled the disengagement, in order to protect the person against future negative experiences. As was the case with students in this study, this return to wellbeing appears to come once young people are given the freedom to select their main activity. 


\section{DISENGAGEMENT TRAJECTORES}

\section{References}

Abbott-Chapman, J., Martin, K., Ollington, N., Venn, A., Dwyer, T., \& Gall, S. (2014) The longitudinal association of childhood school engagement with adult educational and occupational achievement: findings from an Australian national study. British Educational Research Journal, 40(1), 102-120.

Bask, M., \& Salmela-Aro, K. (2013) Burned out to drop out: Exploring the relationship between school burnout and school dropout. European Journal of Psychology of Education, 28(2), 511-528.

Carter, A. C., Brandon, K. O., \& Goldman, M. S. (2010) The college and noncollege experience: a review of the factors that influence drinking behavior in young adulthood. Journal of Studies on Alcohol and Drugs, 71(5), 742-750.

Chowdry, H., Crawford, C., \& Goodman, A. (2011) The role of attitudes and behaviours in explaining socio-economic differences in attainment at age 16. Longitudinal and Life Course Studies, 2(1), 59-76.

Cohen, J. (1992) A power primer. Psychological Bulletin, 112(1), 155-159.

Covington, M. V. (1984) The self-worth theory of achievement motivation: findings and implications. The Elementary School Journal, 85(1), 5-20.

Csikszentmihalyi, M. (1990) Flow: the psychology of optimal experience. New York: Harper \& Row.

Deci, E. L., \& Ryan, R. M. (1985) Intrinsic motivation and self-determination in human behaviour (New York, Plenum Press).

Downes, P. (2011) The neglected shadow: some European perspectives on emotional supports for early school leaving prevention. International Journal of Emotional Education, 3(2), 3-39. 


\section{DISENGAGEMENT TRAJECTORES}

Duckworth, K., \& Schoon, I. (2012) Beating the odds: Exploring the aspects of social risk on young people's school-to-work transitions during recession in the UK. National Institute Economic Review, 222, 38-51.

Durlak, J. A., Weissberg, R. P., Dymnicki, A. B., Taylor, R. D., \& Schellinger, K. B. (2011) The Impact of Enhancing Students' Social and Emotional Learning: A Meta-Analysis of School-Based Universal Interventions. Child Development, 82(1), 405-432.

Eccles, J., Adler, T., Futterman, R. Goff, S., Kaczala, C. Meece, J. \& Midgley, C. (1983) Expectancies, values and academic behavior. In: J. T. Spence Achievement and achievement motivation (pp. 75 - 146). (San Francisco, W. H. Freeman).

Eccles, J., \& Wang, M.-T. (2012) So what is student engagement anyway? In: S. L. Christenson, A. L. Reschly, \& C. Wylie (Eds) Handbook of research on student engagement (pp. 133-145). (New York, Springer).

Eccles, J. S., Wigfield, A., Midgley, C., Reuman, D., Mac Iver, D., \& Feldlaufer, H. (1993) Negative effects of traditional middle schools on students' motivation. The Elementary School Journal, 93(5), 553-574.

Elias, M. J., Zins, J. E., Weissberg, R. P., Frey, K. S., Greenberg, M. T., Haynes, N. M., Kessler, R., Schwab-Stone, M.E. \& Shriver, T. P. (1997) Promoting social and emotional learning: guidelines for educators. Alexandria, VA: Association for Supervision and Curriculum Development.

Ermisch, J., Jäntti, M., \& Smeeding, T. (Eds.). (2012) From parents to children : the intergenerational transmission of advantage. New York: Russell Sage Foundation.

Fulmer, S. M., \& Tulis, M. (2013) Changes in interest and affect during a difficult reading task: Relationships with perceived difficulty and reading fluency. Learning and Instruction, 1(27), 11-20.

Fredricks, J. A., Blumenfeld, P. C., \& Paris, A. H. (2004) School engagement: potential of the concept, state of the evidence. Review of Educational Research, 74(1), 59-109. 


\section{DISENGAGEMENT TRAJECTORES}

Gorard, S., \& Huat See, B. (2010) How can we enhance enjoyment of secondary school? The student view. British Educational Research Journal, 37(4), 671-690.

Green, J., Liem, G. A. D., Martin, A. J., Colmar, S., Marsh, H. W., \& McInerney, D. (2012) Academic motivation, self-concept, engagement, and performance in high school: Key processes from a longitudinal perspective. Journal of Adolescence, 35(5), 11111122.

Hargreaves, D. J. (1984) Improving secondary schools (London, Inner London Education Authority).

Heckhausen, J., Wrosch, C., \& Schulz, R. (2010). A motivational theory of life-span development. Psychological Review, 117(1), 32-60.

Henry, K. L., Knight, K. E., \& Thornberry, T. P. (2012) School disengagement as a predictor of dropout, delinquency, and problem substance use during adolescence and early adulthood. Journal of Youth and Adolescence, 41(2), 156-166.

Hidi, S., \& Renninger, K. A. (2006) The four-phase model of interest development. Educational Psychologist, 41(2), 111-127.

HM Treasury. (2004) Child poverty review. London: Her Majesty's Stationary Office.

Humphrey, N., Lendrum, A., \& Wigelsworth, M. (2010) Social and emotional aspects of learning (SEAL) programme in secondary schools: national evaluation. London: Department for Education. Research Report DFE-RR049.

Janosz, M., Archambault, I., Morizot, J., \& Pagani, L. S. (2008) School Engagement Trajectories and Their Differential Predictive Relations to Dropout. Journal of Social Issues, 64(1), 21-40.

Li, Y., \& Lerner, R. M. (2011) Trajectories of school engagement during adolescence: implications for grades, depression, delinquency, and substance use. Developmental Psychology, 47(1), 223-247. 


\section{DISENGAGEMENT TRAJECTORES}

Li, Y., \& Lerner, R. M. (2013) Interrelations of behavioral, emotional, and cognitive school engagement in high school students. Journal of Youth and Adolescence, 42(1), 20-32.

Little, R., J. A., \& Rubin, D. B. (2014) Statistical analysis with missing data (2nd ed). New Jersey: John Wiley \& Sons, Inc.

Linnenbrink-Garcia, L., Durik, A. M., Conley, A. M., Barron, K. E., Tauer, J. M., Karabenick, S. A., \& Harackiewicz, J. M. (2010) Measuring situational interest in academic domains, 70(4), 647-671. Educational and Psychological Measurement.

Linnenbrink-Garcia, L., Patall, E. A., \& Messersmith, E. E. (2013) Antecedents and consequences of situational interest. British Journal of Educational Psychology, 83(4), 591-614.

Macklem, G. L. (2015). Boredom in the classroom: addressing student motivation, selfregulation and engagement in learning. London: Springer.

Muthén, B., \& Muthén, L. K. (2000) Integrating person-centered and variable-centered analyses: growth mixture modeling with latent trajectory classes. Alcoholism: Clinical and Experimental Research, 24(6), 882-891.

Nagin, D. S., \& Odgers, C. L. (2010) Group-based trajectory modeling in clinical research. Annual Review of Clinical Psychology, 6, 109-138.

O'Keefe, P. A., \& Linnenbrink-Garcia, L. (2014) The role of interest in optimizing performance and self-regulation. Journal of Experimental Social Psychology, 53(1), 70-78.

Parker, P. D., Jerrim, J., Schoon, I., \& Marsh, H. W. (2016) A multination study of socioeconomic inequality in expectations for progression to higher education: the role of between-school tracking and ability stratification. American Educational Research Journal. Advance online publication.

Pekrun, R., Goetz, T., Daniels, L. M., Stupnisky, R. H., \& Perry, R. P. (2010) Boredom in achievement settings: Exploring control-value antecedents and performance 


\section{DISENGAGEMENT TRAJECTORES}

outcomes of a neglected emotion. Journal of Educational Psychology, 102(3), 531549.

Pekrun, R., Goetz, T., \& Titz, W. (2002) Academic emotions in students' self-regulated learning and achievement: a program of qualitative and quantitative research. Educational Psychologist, 37(2), 91-106.

Pekrun, R., \& Linnenbrink-Garcia, L. (2012) Academic emotions and student engagement. In: S. L. Christenson, A. L. Reschly, \& C. Wylie (Eds) Handbook of research on school engagement (pp. 259-282). (New York, Springer).

Pietarinen, J., Soini, T., \& Pyhältö, K. (2014). Students’ emotional and cognitive engagement as the determinants of well-being and achievement in school. International Journal of Educational Research, 67(1), 40-51.

McCoy, S., Smyth, E., Watson, D., \& Darmody, M. (2014) Leaving school in Ireland: a longitudinal study of post-school transitions. (Dublin, Ireland, The Economic and Social Research Institute).

Rimm-Kaufman, S. E., Baroody, A. E., Larsen, R. A. A., Curby, T. W., \& Abry, T. (2015) To what extent do teacher-student interaction quality and student gender contribute to fifth graders' engagement in mathematics learning? Journal of Educational Psychology, 107(1), 170-185.

Ross, A. (2009) Disengagement from education among 14-16 year olds. (London, National Centre for Social Research, Department for Children, Schools and Families).

Salmela-Aro, K., \& Tynkkynen, L. (2012) Gendered pathways in school burnout among adolescents. Journal of Adolescence, 35(4), 929-939.

Salmela-Aro, K., \& Upadyaya, K. (2014a) School burnout and engagement in the context of demands-resources model. British Journal of Educational Psychology, 84(1), 137151. 


\section{DISENGAGEMENT TRAJECTORES}

Salmela-Aro, K., \& Upadyaya, K. (2014b) Developmental trajectories of school burnout: Evidence from two longitudinal studies. Learning and Individual Differences, 36(1), 60-68.

Schafer, J. L., \& Graham, J. W. (2002) Missing Data: Our View of the State of the Art. Psychological Methods, 7(2), 147-177.

Schoon, I. (2008) A transgenerational model of status attainment: The potential mediating role of school motivation and education. National Institute Economic Review, 205, 72-82.

Schoon, I. (2010) Planning for the future: Changing education expectations in three British cohorts. Historical Social Research, 35(2), 99-199.

Schoon, I. (2014) Parental worklessness and the experience of NEET among their offspring. Evidence from the Longitudinal Study of Young People in England (LSYPE). Longitudinal and Life Course Studies, 6(6), 129-150.

Schneider, B., Krajcik, J., Lavonen, J., Salmela-Aro, K., Broda, M., Spicer, J., Bruner, J., Moeller, J., Linnansaari, J., Juuti, K., \& Viljaranta, J. (2016). Investigating optimal learning moments in U.S. and Finnish science classes. Journal of Research in Science Teaching, 53(3), 400-421.

Shernoff, D. J., Kelly, S., Tonks, S. M., Anderson, B., Cavanagh, R. F., Sinha, S., \& Abdi, B. (2016) Student engagement as a function of environmental complexity in high school classrooms. Learning and Instruction. Advance online publication.

Skinner, E., Marchand, G., Furrer, C., \& Kindermann, T. (2008). Engagement and disaffection in the classroom: part of a larger motivational dynamic? Journal of Educational Psychology, 100(4), 765-781.

Skinner, E. A., \& Pitzer, J. R. (2012) Developmental dynamics of student engagement, coping and everyday resilience. In: S. L. Christenson, A. L. Reschly, \& C. Wylie 


\section{DISENGAGEMENT TRAJECTORES}

(Eds) Handbook of research on school engagement (pp. 21-44). (New York, Springer).

Steyer, R., \& Schmitt, M. J. (1990) Latent state-trait models in attitude research. Quality and Quantity, 24(4), 427-445.

Strand, S. 2007 Minority ethnic pupils in the Longitudinal Study of Young People in England (LSYPE). (London, Department for children, schools and families). Research Report No RR002.

Thoemmes, F. J. (2012) Propensity score matching in SPSS. Published in the electronic holdings of the Cornell University Library. http://arxiv.org/abs/1201.6385.

Thoemmes, F. J., \& Kim, E. S. (2011) A Systematic Review of Propensity Score Methods in the Social Sciences. Multivariate Behavioral Research, 46(1), 90-118.

Tuominen-Soini, H., \& Salmela-Aro, K. (2014) Schoolwork engagement and burnout among Finnish high school students and young adults: Profiles, progressions, and educational outcomes. Developmental Psychology, 50(3), 649-662.

Voelkl, K. E. (2012) School identification. In S. L. Christenson, A. L. Reschly, \& C. Wylie (Eds.), Handbook of research on student engagement (pp. 193-218). New York, NY: Springer.

Wang, M.-T., \& Eccles, J. S. (2012) Adolescent Behavioral, Emotional, and Cognitive Engagement Trajectories in School and Their Differential Relations to Educational Success. Journal of Research on Adolescence, 22(1), 31-39.

Wang, M.-T., \& Peck, S. C. (2013) Adolescent educational success and mental health vary across school engagement profiles. Developmental Psychology, 49(7), 1266-1276.

Westling, S. K., Pyhältö, K., Pietarinen, J., \& Soini, T. (2013) How do ninth-graders perceive their involvement in the most meaningful episodes of their school career? International Journal of Educational Research, 58(1), 25-35. 
DISENGAGEMENT TRAJECTORES

1

2

3

4

5

6

7

8

9

10

11

12

13

14

15

16

17

18

19

20

21

22

23

24

25

26

27

28

29

30

31

32

33

34

35

36

37

38

39

40

41

42

43

44

45

46

47

48

49

50

51

52

53

54

55

56

57

58

59

60

\section{Tables and Figures}

Table 1.

Information Criteria Values

\begin{tabular}{rlrrr}
\hline Number of trajectories & BIC & VLMR $p$ & LMR $p$ & Entropy \\
\hline 1 & 62178 & & & \\
2 & 61693 & .000 & .000 & .63 \\
3 & 61387 & .029 & .032 & .67 \\
4 & 61108 & .000 & .000 & .72 \\
5 & 61114 & .187 & .195 & .73 \\
6 & 60968 & .004 & .005 & .75 \\
7 & 60456 & .000 & .000 & .76 \\
$\mathbf{8}$ & $\mathbf{4 4 1 6 4}$ & $\mathbf{. 0 0 0}$ & $\mathbf{. 0 0 0}$ & $\mathbf{. 8 9}$ \\
9 & 43915 & .000 & .000 & .88 \\
10 & 43789 & .000 & .000 & .88 \\
\hline
\end{tabular}

Table 2.

Emotional Disengagement Trajectories

\begin{tabular}{lrrrrrrr}
\hline & \multicolumn{3}{c}{ Intercept } & \multicolumn{3}{l}{ Slope } \\
& $\mathrm{N}$ & \multicolumn{1}{c}{$\%$} & \multicolumn{1}{c}{ Est. } & $S E$ & Est. & $S E$ \\
\hline Engaged/engaging trajectories & 8104 & 59.00 & & & & \\
\hline stable engaged & 5840 & 42.52 & & 2.11 & .01 & $-.05^{* * *}$ & .00 \\
engaging rapidly 1 (from moderately engaged) & 1492 & 1.86 & 1.91 & .02 & $-.20^{* * *}$ & .01 \\
engaging rapidly 2 (from highly engaged) & 485 & 3.53 & 1.77 & .03 & $-.38^{* * *}$ & .01 \\
engaging rapidly 3 (from disengaged) & 287 & 2.09 & 3.10 & .08 & $-.30^{* * *}$ & .04 \\
\hline Disengaged/disengaging trajectories & 5630 & 41.00 & & & & \\
\hline disengaging mildly (from moderately engaged) & 2558 & 18.63 & 2.21 & .02 & $.15^{* * *}$ & .01 \\
disengaging rapidly (from moderately engaged) & 1306 & 9.51 & 2.17 & .03 & $.42^{* * *}$ & .02 \\
disengaging disengaged & 898 & 6.54 & 2.76 & .02 & $.45^{* * *}$ & .01 \\
stable disengaged & 868 & 6.32 & 2.93 & .04 & $.03^{* * *}$ & .02 \\
\hline
\end{tabular}

Notes: $* * *=p<.000,{ }^{* *}=p<.01, *=p<.05$.

Figure 1.

Emotional Disengagement Profiles

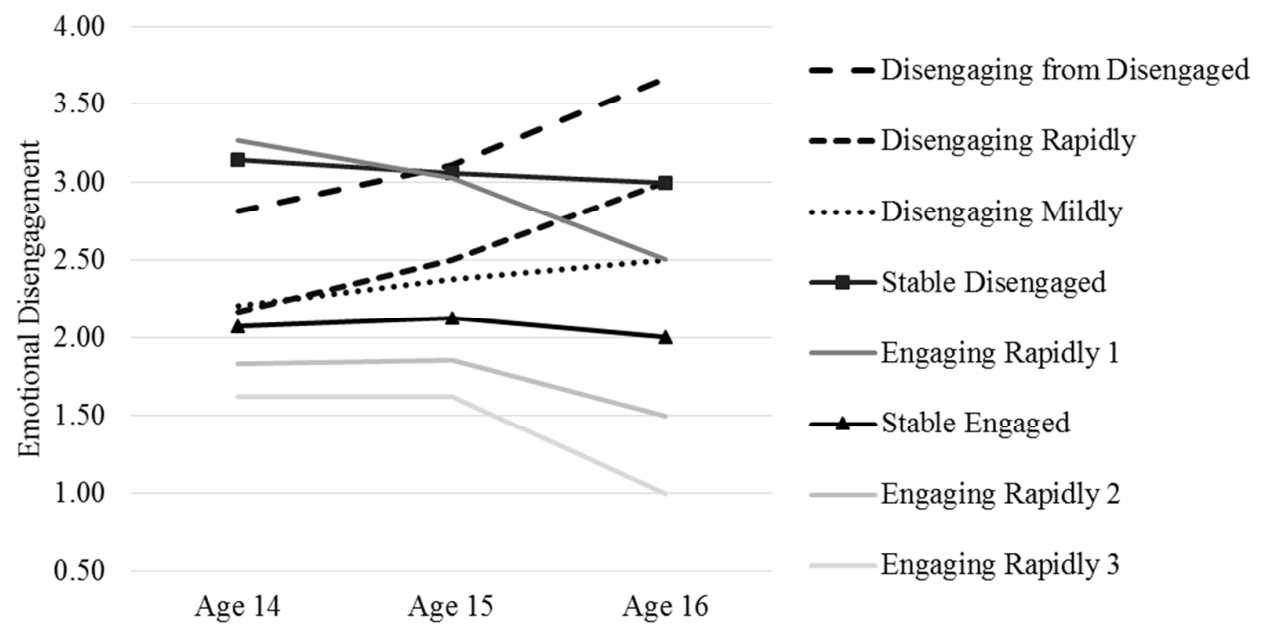

URL: http://mc.manuscriptcentral.com/cber 
Table 3.

Descriptive Statistics and Regression Coefficients for Pre-Matched Groups at Baseline 1

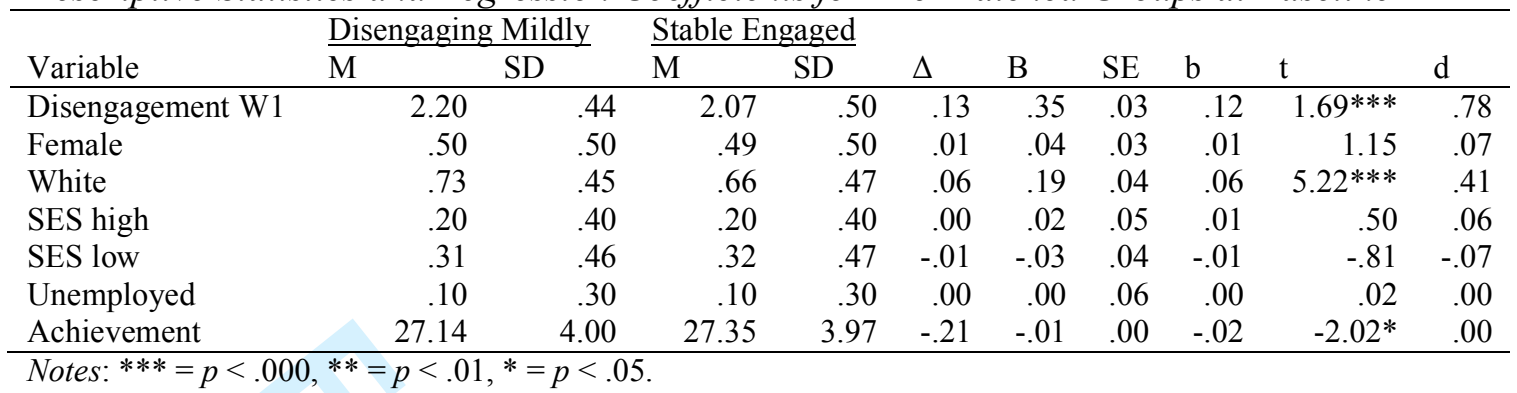

Table 4.

Descriptive Statistics and Regression Coefficients for Pre-Matched Groups at Baseline 2

\begin{tabular}{|c|c|c|c|c|c|c|c|c|c|c|}
\hline \multirow[b]{2}{*}{ Variable } & \multicolumn{2}{|c|}{ Disengaging Rapidly } & \multicolumn{2}{|c|}{ Stable Engaged } & \multirow[b]{2}{*}{$\Delta$} & \multirow[b]{2}{*}{ B } & \multirow[b]{2}{*}{ SE } & \multirow[b]{2}{*}{$\mathrm{b}$} & \multirow[b]{2}{*}{$\mathrm{t}$} & \multirow[b]{2}{*}{$\mathrm{d}$} \\
\hline & $\mathrm{M}$ & $\mathrm{SD}$ & M & SD & & & & & & \\
\hline Disengagement $\mathrm{W} 1$ & 2.16 & .40 & 2.07 & .50 & .09 & .21 & .04 & .06 & $5.08 * * *$ & .44 \\
\hline Female & .46 & .50 & .49 & .50 & -.04 & -.08 & .04 & -.02 & -1.93 & -.15 \\
\hline White & .76 & .43 & .66 & .47 & .10 & .26 & .04 & .08 & $5.93 * * *$ & .58 \\
\hline SES high & .20 & .10 & .20 & .40 & .00 & .00 & .06 & .00 & .00 & .00 \\
\hline SES low & .31 & .46 & .32 & .47 & -.01 & -.04 & .05 & -.01 & -.87 & -.09 \\
\hline Unemployed & .08 & .28 & .10 & .30 & -.02 & -.14 & .07 & -.03 & $-2.04 *$ & -.50 \\
\hline Achievement & 27.06 & 3.76 & 27.35 & 3.97 & -.29 & -.01 & .01 & -.03 & $-2.12 *$ & .00 \\
\hline
\end{tabular}

Notes: $* * *=p<.000, * *=p<.01, *=p<.05$.

Table 5.

Descriptive Statistics and Regression Coefficients for Pre-Matched Groups at Baseline 3

\begin{tabular}{|c|c|c|c|c|c|c|c|c|c|c|}
\hline \multirow[b]{2}{*}{ Variable } & \multicolumn{2}{|c|}{$\underline{\text { Stable Disengaged }}$} & \multicolumn{2}{|c|}{ Stable Engaged } & \multirow[b]{2}{*}{$\Delta$} & \multirow[b]{2}{*}{ B } & \multirow[b]{2}{*}{ SE } & \multirow[b]{2}{*}{$\mathrm{b}$} & \multirow[b]{2}{*}{$\mathrm{t}$} & \multirow[b]{2}{*}{$\mathrm{d}$} \\
\hline & M & SD & M & SD & & & & & & \\
\hline Disengagement $\mathrm{W} 1$ & 3.15 & .36 & 2.07 & .50 & 1.07 & - & - & - & - & - \\
\hline Female & .50 & .50 & .49 & .50 & .01 & .02 & .02 & .01 & .93 & .03 \\
\hline White & .80 & .40 & .66 & .47 & .14 & .16 & .02 & .11 & $8.31 * * *$ & .35 \\
\hline SES high & .20 & .40 & .20 & .40 & .00 & .00 & .02 & .00 & .09 & .01 \\
\hline SES low & .32 & .47 & .32 & .47 & .00 & .00 & .02 & .00 & -.19 & -.01 \\
\hline Unemployed & .09 & .28 & .10 & .30 & -.02 & -.03 & .03 & -.01 & -1.04 & -.11 \\
\hline Achievement & 26.81 & 3.80 & 27.35 & 3.97 & -.54 & -.01 & .00 & -.06 & $-4.39 * * *$ & .00 \\
\hline
\end{tabular}

Table 6.

Descriptive Statistics and Regression Coefficients for Pre-Matched Groups at Baseline 4

\begin{tabular}{|c|c|c|c|c|c|c|c|c|c|c|}
\hline \multirow[b]{2}{*}{ Variable } & \multicolumn{2}{|c|}{ Disengaging Disengaged } & \multicolumn{2}{|c|}{ Stable Disengaged } & \multirow{3}{*}{$\begin{array}{l}\Delta \\
-.33\end{array}$} & \multirow{3}{*}{$\begin{array}{l}\mathrm{B} \\
-.81\end{array}$} & \multirow{2}{*}{\multicolumn{2}{|c|}{$\mathrm{SE} \quad \mathrm{b}$}} & \multirow{2}{*}{$\mathrm{t}$} & \multirow[b]{2}{*}{$\mathrm{d}$} \\
\hline & M & SD & M & SD & & & & & & \\
\hline Disengagement $\mathrm{W} 1$ & 2.81 & .66 & 3.15 & .36 & & & .07 & -.30 & $-12.41 * * *$ & -2.14 \\
\hline Female & .50 & .50 & .50 & .50 & -.01 & -.04 & .07 & -.01 & -.51 & -.07 \\
\hline White & .82 & .39 & .80 & .40 & .01 & .10 & .09 & .03 & 1.09 & .26 \\
\hline SES high & .26 & .44 & .20 & .40 & .06 & .07 & .10 & .02 & .68 & .16 \\
\hline SES low & .26 & .44 & .32 & .47 & -.06 & -.14 & .09 & -.04 & -1.60 & -.31 \\
\hline Unemployed & .06 & .24 & .09 & .28 & -.03 & -.25 & .15 & -.04 & -1.75 & -1.10 \\
\hline Achievement & 25.94 & 4.15 & 26.81 & 3.80 & -.87 & -.03 & .01 & -.09 & $-3.41 * *$ & -.01 \\
\hline
\end{tabular}


DISENGAGEMENT TRAJECTORES

1

2

3

4

5

6

Table 7.

Propensity Score Matched Group Sizes

\begin{tabular}{lrrrlrrr}
\hline Treatment Group & Total & Matched & Unmatched & Comparison Group & Total & Matched & Unmatched \\
\hline Stable disengaged & 868 & 625 & 243 & Stable engaged & 5840 & 1306 & 4534 \\
Disengaging rapidly & 1492 & 1306 & 186 & Stable engaged & 5840 & 2558 & 3282 \\
Disengaging mildly & 2558 & 2558 & 0 & Stable engaged & 868 & 618 & 250 \\
Disengaging disengaged & 898 & 618 & 280 & Stable disengaged & 5840 & 1306 & 4534 \\
\hline
\end{tabular}

Table 8.

Matched Group Outcomes 2 (focus on mild disengagement)

\begin{tabular}{|c|c|c|c|c|c|c|c|c|c|}
\hline & \multicolumn{2}{|c|}{ Disengaging } & \multicolumn{2}{|c|}{ Stable Engaged } & \multicolumn{5}{|c|}{$\underline{\text { Logistic/Linear Regressions }}$} \\
\hline & $\frac{\text { Mildly }}{M}$ & SD & M & SD & $\Delta$ & B & $\mathrm{SE}$ & $\mathrm{d}$ & OR \\
\hline \multicolumn{10}{|l|}{ End of School } \\
\hline Disengagement age 16 & 2.50 & .00 & 2.00 & .00 & .50 & $.50 * * *$ & 0 & 61.82 & - \\
\hline Effort age 16 & 2.10 & .64 & 1.91 & .57 & .19 & $.19 * * *$ & .018 & .32 & - \\
\hline Truancy age 16 & 1.41 & .77 & 1.23 & .57 & .18 & $.18^{* * *}$ & .020 & .26 & - \\
\hline University aspiration age 16 & 2.88 & 1.11 & 2.98 & 1.06 & -.10 & $-.10 * *$ & .032 & -.09 & - \\
\hline GCSE points age 16 & 377.04 & 151.26 & 393.39 & 145.21 & -16.36 & $-16.36^{* * *}$ & 4.172 & -.11 & - \\
\hline Parental relationship age 16 & 3.68 & .52 & 3.72 & .50 & -.04 & $-.04 * *$ & .016 & -.09 & - \\
\hline Bullying age 16 & .31 & .46 & .23 & .42 & .08 & $.08^{* * *}$ & .013 & .18 & - \\
\hline Smoking age 16 & 1.94 & 1.75 & 1.64 & 1.48 & .30 & $.30 * * *$ & .048 & .18 & - \\
\hline Alcohol age 16 & 3.33 & 1.91 & 3.04 & 1.85 & .29 & $.30 * * *$ & .056 & .15 & - \\
\hline Cannabis age 16 & .27 & .45 & .21 & .41 & .06 & $.06^{* * *}$ & .013 & .15 & - \\
\hline Anxiety age 15 & 1.93 & .77 & 1.83 & .71 & .09 & $.09 * * *$ & .021 & .13 & - \\
\hline Depression age 15 & 1.75 & .80 & 1.68 & .75 & .08 & $.08 * * *$ & .022 & .10 & - \\
\hline \multicolumn{10}{|l|}{ Late Adolescence } \\
\hline Full time education age 17 & .78 & .41 & .82 & .38 & -.04 & $-.25 * *$ & .079 & -.66 & .78 \\
\hline Work age 17 & .10 & .30 & .08 & .26 & .03 & $.31 * *$ & .112 & 1.32 & 1.37 \\
\hline Unemployed age 17 & .05 & 21 & .04 & .20 & .00 & .12 & .153 & .59 & 1.12 \\
\hline Anxiety age 17 & 2.04 & .74 & 1.96 & .73 & .08 & $.09 * * *$ & .023 & .11 & - \\
\hline Depression age 17 & 1.74 & .77 & 1.64 & .74 & .09 & $.10^{* * *}$ & .023 & .13 & - \\
\hline \multicolumn{10}{|l|}{ Young Adulthood } \\
\hline University age $19 / 20$ & .48 & .50 & .51 & .50 & -.03 & -.10 & .069 & -.20 & .90 \\
\hline Further Education age $19 / 20$ & .25 & .43 & .24 & .43 & .01 & .03 & .081 & .07 & 1.03 \\
\hline Work age $19 / 20$ & .43 & .50 & .42 & .49 & .02 & .07 & .069 & .13 & 1.07 \\
\hline Unemployed age $19 / 20$ & .12 & .33 & .10 & .30 & .02 & $.23 *$ & .111 & .78 & 1.26 \\
\hline Salary age 20 & 2.42 & 1.16 & 2.36 & 1.17 & .06 & .01 & .01 & .01 & - \\
\hline Drinking age $19 / 20$ & 4.25 & 1.67 & 4.20 & 1.67 & .04 & .04 & .055 & .05 & - \\
\hline Cannabis age $19 / 20$ & .96 & .20 & .97 & .18 & -.01 & -.28 & .179 & -.17 & .76 \\
\hline Life satisfaction age 20 & 3.97 & .91 & 4.02 & .87 & -.04 & -.04 & .03 & -.05 & - \\
\hline
\end{tabular}

Notes: $\mathrm{OR}=$ odds ratios.

Results with odds ratios are binary logistic regressions. Results without odds ratios are linear regressions.

$* * *=p<.000, * *=p<.01, *=p<.05$. 
Table 9.

Matched Group Outcomes 3 (focus on rapid disengagement)

\begin{tabular}{|c|c|c|c|c|c|c|c|c|c|}
\hline & \multirow{2}{*}{\multicolumn{2}{|c|}{$\begin{array}{l}\text { Disengaging } \\
\text { Rapidly }\end{array}$}} & \multirow{2}{*}{\multicolumn{2}{|c|}{ Stable Engaged }} & \multirow{2}{*}{\multicolumn{5}{|c|}{$\underline{\text { Logistic/Linear Regressions }}$}} \\
\hline & & & & & & & & & \\
\hline & $\mathrm{M}$ & SD & M & SD & $\Delta$ & B & SE & $\mathrm{d}$ & OR \\
\hline \multicolumn{10}{|l|}{ End of School } \\
\hline Disengagement age 16 & 3.00 & .00 & 2.00 & .00 & 1.00 & $1.00 * * *$ & .00 & 16.42 & - \\
\hline Effort age 16 & 2.35 & .67 & 1.91 & .57 & .45 & $.45^{* * *}$ & .026 & .71 & - \\
\hline Truancy age 16 & 1.56 & .90 & 1.23 & .57 & .33 & $.33 * * *$ & .032 & .43 & - \\
\hline University aspiration age 16 & 2.59 & 1.12 & 2.87 & 1.10 & -.28 & $-.28 * * *$ & .046 & -.25 & - \\
\hline GCSE points age 16 & 357.47 & 15.88 & 384.54 & 146.48 & -27.08 & $-27.08 * * *$ & 5.851 & -.18 & - \\
\hline Parental relationship age 16 & 3.62 & .55 & 3.71 & .51 & -.09 & $-.09 * * *$ & .022 & -.16 & - \\
\hline Bullying age 16 & .34 & .47 & .24 & .43 & .10 & $.10^{* * *}$ & .019 & .22 & - \\
\hline Smoking age 16 & 2.29 & 2.01 & 1.76 & 1.63 & .53 & $.53 * * *$ & .076 & .29 & - \\
\hline Alcohol age 16 & 3.59 & 1.95 & 3.15 & 1.87 & .44 & $.44 * * *$ & .080 & .23 & - \\
\hline Cannabis age 16 & .32 & .47 & .21 & .41 & .11 & $.11^{* * *}$ & .018 & .25 & - \\
\hline Anxiety age 15 & 1.96 & .81 & 1.81 & .73 & .15 & $.15^{* * *}$ & .031 & .19 & - \\
\hline Depression age 15 & 1.81 & .85 & 1.64 & .74 & .18 & $.18^{* * *}$ & .032 & .22 & - \\
\hline \multicolumn{10}{|l|}{ Late Adolescence } \\
\hline Full time education age 17 & .71 & .45 & .82 & .38 & -.11 & $-.64 * * *$ & 107 & -2.30 & .53 \\
\hline Work age 17 & .12 & .33 & .07 & .26 & .05 & $.56^{* * *}$ & .154 & 5.71 & 1.75 \\
\hline Unemployed age 17 & .07 & .25 & .05 & .21 & .02 & $.40 *$ & .195 & 3.44 & 1.49 \\
\hline Anxiety age 17 & 2.05 & .77 & 1.90 & .72 & .16 & $.16^{* * *}$ & .032 & .21 & - \\
\hline Depression age 17 & 1.80 & .82 & 1.61 & .73 & .20 & $.20 * * *$ & .033 & .25 & - \\
\hline \multicolumn{10}{|l|}{ Young Adulthood } \\
\hline University age $19 / 20$ & .41 & .49 & .48 & .50 & -.08 & $-.31 * *$ & .099 & -.65 & .74 \\
\hline Further Education age $19 / 20$ & .23 & .42 & .22 & .41 & .01 & .059 & .118 & .14 & 1.06 \\
\hline Work age $19 / 20$ & .49 & .50 & .46 & .50 & .03 & .116 & .098 & .23 & 1.12 \\
\hline Unemployed age $19 / 20$ & .15 & .36 & .10 & .31 & .05 & $.45^{* *}$ & .150 & 1.83 & 1.57 \\
\hline Salary age 20 & 2.45 & 1.12 & 2.46 & 1.21 & -.01 & .00 & .02 & .00 & - \\
\hline Drinking age $19 / 20$ & 4.35 & 1.63 & 4.27 & 1.63 & .08 & .075 & .076 & .08 & - \\
\hline Cannabis age $19 / 20$ & .95 & .21 & .97 & .18 & -.01 & -.273 & 248 & -.17 & .76 \\
\hline Life satisfaction age 20 & 3.80 & .96 & 4.03 & .86 & -.23 & $-.23 * * *$ & .05 & -.25 & \\
\hline
\end{tabular}

Notes: $\mathrm{OR}=$ odds ratios.

Results with odds ratios are binary logistic regressions. Results without odds ratios are linear regressions. $* * *=p<.000, * *=p<.01, *=p<.05$. 
1

2

3

4

5

Table 1.

Matched Group Outcomes 1(focus on stable disengagement)

\begin{tabular}{|c|c|c|c|c|c|c|c|c|c|}
\hline & \multicolumn{2}{|c|}{ Stable Disengaged } & \multicolumn{3}{|c|}{ Stable Engaged } & \multicolumn{4}{|c|}{ Logistic/Linear Regressions } \\
\hline & $\mathrm{M}$ & $\mathrm{SD}$ & $\mathrm{M}$ & SD & $\Delta$ & $\mathrm{B}$ & SE & $\mathrm{d}$ & OR \\
\hline \multicolumn{10}{|l|}{ End of School } \\
\hline Disengagement age 16 & 3.00 & .00 & 2.00 & .00 & 1.00 & $1.00^{* * *}$ & .00 & 63.10 & \\
\hline Effort age 16 & 2.50 & .68 & 2.03 & .60 & .47 & $.47^{* * *}$ & .040 & .74 & \\
\hline Truancy age 16 & 1.65 & .95 & 1.32 & .65 & .33 & $.33 * * *$ & .052 & .40 & \\
\hline spiration age 16 & 2.40 & 1.12 & 2.66 & 1.12 & -.26 & $-.26 * * *$ & .070 & -.23 & \\
\hline GCSE points age 16 & 33.48 & 154.38 & 352.06 & 153.46 & -21.59 & $-21.59 *$ & 8.795 & -.14 & . \\
\hline Parental relationship age 16 & 3.58 & .58 & 3.68 & .52 & -.10 & $-.10 * *$ & .035 & -.18 & \\
\hline Bully & .34 & .47 & .26 & .44 & .0 & & .028 & .17 & \\
\hline Smok & 2.64 & 2.15 & 2.00 & 1.84 & .6 & $.65^{* * *}$ & .125 & .32 & . \\
\hline Alcohol age 16 & 3.94 & 1.85 & 3.20 & 1.91 & .74 & $.74 * * *$ & .118 & .39 & - \\
\hline Canr & .45 & .50 & .27 & .44 & .19 & $.19 * * *$ & .029 & .39 & \\
\hline Anxi & 1.99 & .82 & 1.88 & .74 & .1 & $.11 *$ & .045 & .14 & \\
\hline Depression age 15 & 1.91 & .91 & 1.77 & .81 & .14 & $.14 * *$ & .049 & .16 & - \\
\hline \multicolumn{10}{|l|}{ Late Adolescence } \\
\hline In full time edu & .64 & .48 & .73 & .45 & -.08 & $-.39 * *$ & .143 & -.94 & .674 \\
\hline Work & .15 & .36 & .09 & .29 & .06 & $.60 * *$ & .206 & 4.38 & 1.819 \\
\hline d age 17 & .08 & .27 & .08 & .27 & .00 & -.044 & .244 & -.16 & .957 \\
\hline & 2.05 & .73 & 1.94 & .78 & .11 & $.11 *$ & .048 & .15 & - \\
\hline Depression age 17 & 1.78 & .81 & 1.70 & .83 & .0 & .08 & .052 & .10 & \\
\hline \multicolumn{10}{|l|}{ Young Adulthood } \\
\hline University age $19 / 20$ & .34 & .47 & .42 & .49 & -.08 & $-.36 *$ & .156 & -.79 & 699 \\
\hline ge $19 / 20$ & .26 & .44 & .23 & .42 & & .19 & .176 & .45 & 1.208 \\
\hline Work & .53 & .50 & .53 & .50 & .00 & .01 & .148 & .03 & 1.013 \\
\hline Unemployed age 19/20 & .13 & .34 & .12 & .32 & .02 & .16 & .228 & .51 & 1.177 \\
\hline Salary & 2.70 & 1.24 & 2.53 & 1.15 & .1 & .03 & .02 & .01 & \\
\hline & 4.46 & 1.39 & 4.31 & 1.58 & .1 & .15 & .106 & .10 & \\
\hline Cannabis age $19 / 20$ & .96 & .19 & .97 & .17 & -.01 & -.27 & .404 & -2.23 & .762 \\
\hline Life satisfaction age 20 & 3.73 & 1.06 & 3.89 & .96 & -.15 & $-.16^{*}$ & .08 & -.15 & \\
\hline
\end{tabular}

Notes: $\mathrm{OR}=$ odds ratios.

Results with odds ratios are binary logistic regressions. Results without odds ratios are linear regressions. $* * *=p<.000, * *=p<.01, *=p<.05$. 
Table 11.

Matched Group Outcomes 4 (focus on disengaging from disengaged baseline)

\begin{tabular}{|c|c|c|c|c|c|c|c|c|c|}
\hline & \multirow{2}{*}{\multicolumn{2}{|c|}{$\frac{\text { Disengaging }}{\text { Disengaged }}$}} & \multirow{2}{*}{\multicolumn{2}{|c|}{$\frac{\text { Stable }}{\text { Disengaged }}$}} & \multicolumn{5}{|c|}{$\underline{\text { Logistic/Linear Regressions }}$} \\
\hline & & & & & \multirow[b]{2}{*}{$\Delta$} & \multirow[b]{2}{*}{ B } & \multirow[b]{2}{*}{ SE } & \multirow[t]{2}{*}{. } & \multirow[b]{2}{*}{ OR } \\
\hline & M & SD & $\mathrm{M}$ & SD & & & & & \\
\hline \multicolumn{10}{|l|}{ End of School } \\
\hline Disengagement age 16 & 3.66 & .23 & 3.00 & .00 & .66 & $.66^{* * *}$ & .01 & 3.95 & - \\
\hline Effort age 16 & 2.71 & .85 & 2.49 & .70 & .22 & $.22 * * *$ & .05 & .28 & - \\
\hline Truancy age 16 & 1.97 & 1.14 & 1.67 & .98 & .30 & $.30 * * *$ & .07 & .28 & - \\
\hline University aspiration age 16 & 2.17 & 1.17 & 2.25 & 1.11 & -.09 & -.09 & .07 & -.07 & - \\
\hline GCSE points age 16 & 289.52 & 164.15 & 312.52 & 157.07 & -23.00 & $-23.00 *$ & 9.32 & -.14 & - \\
\hline Parental relationship age 16 & 3.54 & .60 & 3.57 & .61 & -.03 & -.03 & .04 & -.06 & - \\
\hline Bullying age 16 & .42 & .49 & .35 & .48 & .07 & $.07 *$ & .03 & .14 & - \\
\hline Smoking age 16 & 3.00 & 2.27 & 2.76 & 2.19 & .24 & .24 & .14 & .11 & - \\
\hline Alcohol age 16 & 4.39 & 1.93 & 3.98 & 1.90 & .42 & $.42 *$ & .12 & .22 & - \\
\hline Cannabis age 16 & .52 & .50 & .44 & .50 & .07 & $.07 *$ & .03 & .15 & - \\
\hline Anxiety age 15 & 2.14 & .89 & 2.05 & .84 & .09 & .09 & .05 & .10 & - \\
\hline Depression age 15 & 2.09 & .97 & 1.98 & .94 & .11 & $.11 *$ & .06 & .12 & - \\
\hline \multicolumn{10}{|l|}{ Late Adolescence } \\
\hline Full time education age 17 & .53 & .50 & .62 & .48 & -.10 & $-.39 * *$ & .14 & -.87 & .68 \\
\hline Work age 17 & .22 & .41 & .16 & .36 & .06 & $.41 *$ & .17 & 1.23 & 1.50 \\
\hline Unemployed age 17 & .13 & .34 & .10 & .30 & .03 & .34 & .21 & 1.27 & 1.40 \\
\hline Anxiety age 17 & 2.18 & .86 & 2.05 & .75 & .13 & $.13 * *$ & .05 & .16 & - \\
\hline Depression age 17 & 1.97 & .93 & 1.82 & .85 & .14 & $.14^{* *}$ & .06 & .16 & - \\
\hline \multicolumn{10}{|l|}{ Young Adulthood } \\
\hline University age $19 / 20$ & .28 & .45 & .30 & .46 & -.02 & -.09 & .17 & -.20 & .91 \\
\hline Further Education age 19/20 & .20 & .40 & .28 & .45 & -.08 & $-.42 *$ & .18 & -1.12 & .66 \\
\hline Work age $19 / 20$ & .58 & .49 & .56 & .50 & .02 & .10 & .15 & .20 & 1.10 \\
\hline Unemployed age 19/20 & .22 & .41 & .15 & .36 & .07 & $.46^{*}$ & .20 & 1.48 & 1.59 \\
\hline Salary age 20 & 2.60 & 1.09 & 2.68 & 1.18 & -.08 & -.01 & .02 & .00 & - \\
\hline Drinking age $19 / 20$ & 4.38 & 1.66 & 4.45 & 1.47 & -.08 & -.08 & .11 & -.07 & - \\
\hline Cannabis age $19 / 20$ & .96 & .20 & .96 & .19 & -.01 & -.13 & .37 & -.08 & .88 \\
\hline Life satisfaction age 20 & 3.72 & 1.06 & 3.72 & 1.07 & .00 & .00 & .08 & .00 & \\
\hline
\end{tabular}

Notes: $\mathrm{OR}=$ odds ratios.

Results with odds ratios are binary logistic regressions. Results without odds ratios are linear regressions. $* * *=p<.000, * *=p<.01, *=p<.05$. 